\title{
Recombination of Virulence Genes in Divergent Acidovorax avenae Strains That Infect a Common Host
}

\author{
Quan Zeng, ${ }^{1,+}$ Jie Wang, ${ }^{2}$ Frederic Bertels, ${ }^{3}$ Paul R. Giordano, ${ }^{2}$ Martin I. Chilvers, ${ }^{2}$ Regan B. Huntley, ${ }^{1}$ \\ Joseph M. Vargas, ${ }^{2}$ George W. Sundin, ${ }^{2}$ Janette L. Jacobs, ${ }^{2}$ and Ching-Hong Yang ${ }^{4}$ \\ ${ }^{1}$ Department of Plant Pathology and Ecology, The Connecticut Agricultural Experiment Station, New Haven, CT 06504, U.S.A.; \\ ${ }^{2}$ Department of Plant, Soil, and Microbial Sciences, Michigan State University, East Lansing, MI 48824, U.S.A.; ${ }^{3}$ Department for \\ Evolutionary Theory, Max Planck Institute for Evolutionary Biology, Plön 24306, Germany; and ${ }^{4}$ Department of Biological \\ Sciences, University of Wisconsin-Milwaukee, Milwaukee, WI 53211, U.S.A.
}

Accepted 9 March 2017.

\begin{abstract}
Bacterial etiolation and decline (BED), caused by Acidovorax avenae, is an emerging disease of creeping bentgrass on golf courses in the United States. We performed the first comprehensive analysis of $A$. avenae on a nationwide collection of turfgrass- and maize-pathogenic $A$. avenae. Surprisingly, our results reveal that the turfgrass-pathogenic $A$. avenae in North America are not only highly divergent but also belong to two distinct phylogroups. Both phylogroups specifically infect turfgrass but are more closely related to maize pathogens than to each other. This suggests that, although the disease is only recently reported, it has likely been infecting turfgrass for a long time. To identify a genetic basis for the host specificity, we searched for genes closely related among turfgrass strains but distantly related to their homologs from maize strains. We found a cluster of 11 such genes generated by three ancient recombination events within the type III secretion system (T3SS) pathogenicity island. Ever since the recombination, the cluster has been conserved by strong purifying selection, hinting at its selective importance. Together our analyses suggest that BED is an ancient disease that may owe its host specificity to a highly conserved cluster of 11 T3SS genes.
\end{abstract}

Crop domestication, a process in which a single species of agriculturally important plants were selected and densely grown on agricultural farmland, represents an important milestone in the history of human civilization (Doebley et al. 2006). This process, while providing human beings with reliable food supplies, reduced genetic diversity and increased host density of the agricultural farmland, by replacing a variety of natural plant species with a single, genetically homogenous cultivar (Stukenbrock and McDonald 2008). The reduction of genetic diversity and increased density of crop species allows

Q. Zeng., J. Wang., F. Bertels, and P. R. Giordano contributed equally to this work.

Current address for Paul R. Giordano: Division of Environmental Science, Bayer CropScience LP, Guelph, Ontario, Canada.

${ }^{\dagger}$ Corresponding author: Q. Zeng; E-mail: Quan.Zeng@ct.gov

*The $\boldsymbol{e}$-Xtra logo stands for "electronic extra" and indicates that five supplementary figures are published online.

(c) 2017 The American Phytopathological Society pathogens to evolve from being less virulent to multiple plant species to highly virulent to a single or limited number of plant species (Monteil et al. 2013; Stukenbrock and McDonald 2008). Understanding how a plant pathogen increases in virulence and emerges from a diverse environmental population and the evolutionary mechanisms behind this process can often provide indications for the future mitigation of plant diseases.

There are many recent reports of emergent plant disease that are usually caused by the spread of a clonal pathogen population (Ailloud et al. 2015; Marcelletti and Scortichini 2016; McCann et al. 2013; Menardo et al. 2016). For example the olive quick decline syndrome in southern Italy was caused by a highly clonal population of the bacterial pathogen Xylella fastidiosa subsp. pauca (Marcelletti and Scortichini 2016). This clonal population probably emerged from a diverse population of $X$. fastidiosa strains that infect coffee plants in central Africa. Putative prophage-like regions were detected in the genomes of four subsp. pauca clonal strains. As prophage-like elements play an important role in virulence and adaptation of $X$. fastidiosa to new hosts, it was suggested that these elements play a role in host adaptation and pathogen emergence, although experimental validation is needed. In another study, a new virulent population of the apple scab pathogen Venturia inaequalis, which can infect apple (Malus $\times$ domestica) varieties carrying $R v i 6$ resistance, has not emerged from the resident apple pathogen populations but, rather, from a population that infects the wild host Malus floribunda (Lemaire et al. 2016).

Here, we are focusing on a subset of Acidovorax avenae strains that infect creeping bentgrass (Agrostis stolonifera L.). Compared with many food crops (domestication started 4,000 to 10,000 years ago [Balter 2007; Doebley et al. 2006]), domestication of creeping bentgrass is fairly recent, coinciding with the rise in popularity of the game of golf. Originating in the United Kingdom in the 15th century, golf was introduced to the United States in the late 19th century. Increased popularity of golf in the 20th century in the United States not only resulted in the establishment of a large number of golf courses throughout the country $(17,672$ courses, accounting for $50 \%$ of golf courses worldwide) (Ikki-Shuppan 2008) but also the adaptation of specific grass species to putting greens and fairways. Creeping bentgrass has many desirable traits for growth on golf course putting greens. These include the production of vigorous spreading stolons, dense growth, short mowing tolerance, and beautiful coloration. In addition, as one of the cool-season grasses, creeping bentgrass can tolerate cold temperatures in the winter and prefers to grow at a temperature range between 
Table 1. Genomes and Acidovorax strains used in this study

\begin{tabular}{|c|c|c|c|c|c|}
\hline Isolate & Bacteria & Origin & Year & Host & Phylogroup \\
\hline COLB1 & A. avenae & Texas & 2010 & Creeping bentgrass 'Penn A4' & 2 \\
\hline INDB2 & A. avenae & Indiana & 2010 & Creeping bentgrass ${ }^{\mathrm{b}}$ & 2 \\
\hline INV & A. avenae & Ohio & 2010 & Creeping bentgrass & 1 \\
\hline KL3 & A. avenae & Ohio & 2010 & Creeping bentgrass & 1 \\
\hline MD5 & A. avenae & Illinois & 2010 & Creeping bentgrass & 2 \\
\hline MDB1 & A. avenae & Maryland & 2010 & Creeping bentgrass & 1 \\
\hline MOR & A. avenae & Ohio & 2010 & Creeping bentgrass & 2 \\
\hline NCT3 & A. avenae & North Carolina & 2011 & Creeping bentgrass 'Penn G2' & 1 \\
\hline QH1 & A. avenae & North Carolina & 2009 & Creeping bentgrass 'Penn G2' & 2 \\
\hline QHB1 & A. avenae & North Carolina & 2009 & Creeping bentgrass 'Penn G2' & 1 \\
\hline $\mathrm{Sa} 2$ & A. avenae & Pennsylvania & 2011 & Creeping bentgrass 'Alpha' & 1 \\
\hline SF12 & A. avenae & New York & 2011 & Creeping bentgrass & 2 \\
\hline SH7 & A. avenae & Rhode Island & 2010 & Colonial Bentgrass 'Greenwich' & 2 \\
\hline URI_9 & A. avenae & Massachusetts & 2010 & Creeping bentgrass & 1 \\
\hline MSU_2 & A. avenae & Texas & 2010 & Creeping bentgrass 'Penn A4' & 2 \\
\hline MSU_8 & A. avenae & Indiana & 2010 & Creeping bentgrass & 2 \\
\hline MSU_13 & A. avenae & North Carolina & 2011 & Creeping bentgrass 'Penn G2' & 1 \\
\hline MSU_14 & A. avenae & North Carolina & 2011 & Creeping bentgrass 'Penn G2' & 2 \\
\hline MSU_15 & A. avenae & Idaho & 2012 & Creeping bentgrass & 1 \\
\hline MSU_19 & A. avenae & Michigan & 2012 & Creeping bentgrass & 1 \\
\hline URI_1 & A. avenae & Connecticut & 2010 & Creeping bentgrass & 1 \\
\hline URI_2 & A. avenae & Massachusetts & 2010 & Creeping bentgrass & 2 \\
\hline URI_4 & A. avenae & New Jersey & 2010 & Creeping bentgrass & 2 \\
\hline URI_6 & A. avenae & Virginia & 2010 & Creeping bentgrass 'L-93' & 1 \\
\hline URI_10 & A. avenae & North Carolina & 2010 & Creeping bentgrass & 2 \\
\hline URI_16 & A. avenae & Michigan & 2011 & Creeping bentgrass & 1 \\
\hline URI_17 & A. avenae & Rhode Island & 2011 & Creeping bentgrass & 2 \\
\hline URI_18 & A. avenae & New York & 2011 & Creeping bentgrass & 2 \\
\hline AA78_5 & A. avenae & Georgia & 1978 & Maize & $\mathrm{n} / \mathrm{a}$ \\
\hline AA81_1 & A. avenae & Georgia & 1981 & Maize & $\mathrm{n} / \mathrm{a}$ \\
\hline AA99_2 & A. avenae & Georgia & 1999 & Maize & $\mathrm{n} / \mathrm{a}$ \\
\hline CAT98_1 & A. cattleyae & California & $\mathrm{n} / \mathrm{a}$ & Orchid & $\mathrm{n} / \mathrm{a}$ \\
\hline ATCC 19860 & A. avenae & United States & 1909 & Maize & $\mathrm{n} / \mathrm{a}$ \\
\hline AAC00-1 & A. citrulli & United States & 1990 & Watermelon & $\mathrm{n} / \mathrm{a}$ \\
\hline AA_30003 & A. avenae & Japan & $\mathrm{n} / \mathrm{a}^{\mathrm{c}}$ & Rice & $\mathrm{n} / \mathrm{a}$ \\
\hline $\mathrm{AA} \_30015$ & A. avenae & Nigeria & $\mathrm{n} / \mathrm{a}$ & Rice & $\mathrm{n} / \mathrm{a}$ \\
\hline AA_30044 & A. avenae & Nigeria & $\mathrm{n} / \mathrm{a}$ & Millet & $\mathrm{n} / \mathrm{a}$ \\
\hline AA_30179 & A. avenae & Brazil & $\mathrm{n} / \mathrm{a}$ & Sorghum & $\mathrm{n} / \mathrm{a}$ \\
\hline AA_30296 & A. avenae & Japan & $\mathrm{n} / \mathrm{a}$ & Rice & $\mathrm{n} / \mathrm{a}$ \\
\hline AA_30297 & A. avenae & Japan & $\mathrm{n} / \mathrm{a}$ & Rice & $\mathrm{n} / \mathrm{a}$ \\
\hline AA_30298 & A. avenae & Japan & $\mathrm{n} / \mathrm{a}$ & Rice & $\mathrm{n} / \mathrm{a}$ \\
\hline AA_30305 & A. avenae & United States & $\mathrm{n} / \mathrm{a}$ & Vasey grass & $\mathrm{n} / \mathrm{a}$ \\
\hline KONJ & A. konjaci & Japan & $\mathrm{n} / \mathrm{a}$ & Konjac & $\mathrm{n} / \mathrm{a}$ \\
\hline CIT92_17 & A. citrulli & Georgia & $\mathrm{n} / \mathrm{a}$ & Melon & $\mathrm{n} / \mathrm{a}$ \\
\hline CIT92_300 & A. citrulli & Georgia & $\mathrm{n} / \mathrm{a}$ & Melon & $\mathrm{n} / \mathrm{a}$ \\
\hline CIT96_9 & A. citrulli & Georgia & $\mathrm{n} / \mathrm{a}$ & Melon & $\mathrm{n} / \mathrm{a}$ \\
\hline
\end{tabular}

${ }^{\text {a }}$ GC = guanine-cytosine; NCBI = National Center for Biotechnology Information.

${ }^{b}$ If cultivar information is not labeled, it means the cultivar of the host is unknown.

${ }^{\mathrm{c}} \mathrm{n} / \mathrm{a}=$ not applicable or not available.

${ }^{\mathrm{d}}$ S. Lucas, A. Copeland, A. Lapidus, J.-F. Cheng, L. Goodwin, S. Pitluck, O. Chertkov, B. Held, J. C. Detter, C. Han, R. Tapia, M. Land, L. Hauser, N. Kyrpides, N. Ivanova, G. Ovchinnikova, I. Pagani, S. Gordon, and T. Woyke.

e A. Copeland, S. Lucas, A. Lapidus, K. Barry, J. C. Detter, T. Glavina del Rio, E. Dalin, H. Tice, S. Pitluck, H. Kiss, T. Brettin, D. Bruce, C. Han, R. Tapia, P. Gilna, J. Schmutz, F. Larimer, M. Land, L. Hauser, N. Kyrpides, E. Kim, D. Stahl, and P. Richardson.

${ }^{\mathrm{f}} \mathrm{PAMDB}=$ Plant-Associated Microbes Database.

15 and $24^{\circ} \mathrm{C}$. Due to these reasons, creeping bentgrass has become the most widely used turfgrass species on golf course putting greens in the United States (Bonos and Murphy 2009).

In 2009 to 2012, a new turfgrass disease was reported on creeping bentgrass from many golf courses in the United States (Giordano et al. 2010). This disease occurred over a wide range of geographical regions in the United States, including 15 states mostly located in the mid-Atlantic, southeast, and midwest regions. Infected turfgrass displayed symptoms of chlorosis, elongation of the leaf blades, necrosis, and decline (Giordano et al. 2010, 2012). This disease often occurred on grass that was intensively maintained under hot, stressful weather conditions in the summer. The causal agent was later diagnosed to be the bacterium Acidovorax avenae (formerly known as Acidovorax avenae subsp. avenae and Pseudomonas avenae) (Giordano et al. 2010, 2012). The pathogenic A. avenae isolates can infect and colonize the vascular tissue of creeping bentgrass (Giordano et al. 2012). The host range of the pathogens is mostly restricted to creeping bentgrass (Agrostis stolonifera), with only mild pathogenicity to other grass hosts (Giordano et al. 2012). This disease was named, after the causal agent (bacterium) and the symptoms (etiolation and decline), bacterial etiolation and decline (BED). In a previous study, 28 A. avenae specimens were isolated from infected creeping bentgrass with BED symptoms and the virulence of these isolates was confirmed in growthchamber pathogenicity tests (Giordano et al. 2012).

Diseases caused by $A$. avenae have been reported for many plants in the Poaceae family since the beginning of the 20th 
Table 1. (continued from previous page)

\begin{tabular}{|c|c|c|c|c|c|c|}
\hline No. contigs & Largest contigs & Total length & $\mathrm{GC}^{\mathbf{a}}(\%)$ & N50 & NCBI accession & Reference \\
\hline 191 & 208,047 & $5,517,506$ & 68.4 & 76,320 & SRR4096853 & This study \\
\hline 279 & 158,622 & $5,679,539$ & 68.1 & 45,561 & SRR4096854 & This study \\
\hline 269 & 166,406 & $5,750,708$ & 68.2 & 61,274 & SRR4096855 & This study \\
\hline 296 & 148,999 & $5,499,225$ & 68.4 & 38,955 & SRR4096856 & This study \\
\hline 1 & $5,93,846$ & $5,593,846$ & 68.4 & $5,593,846$ & SRR4096857 & This study \\
\hline 161 & 522,546 & $5,663,181$ & 68.3 & 107,765 & SRR4096858 & This study \\
\hline 2,909 & 213,018 & $7,943,278$ & 58.8 & 26,289 & SRR4096819 & This study \\
\hline 221 & 260,470 & $5,519,745$ & 68.4 & 65,391 & SRR4096820 & This study \\
\hline 169 & 205,103 & $5,541,121$ & 68.3 & 69,933 & SRR4096821 & This study \\
\hline 173 & 274,288 & $5,726,390$ & 68.3 & 95,527 & SRR4096822 & This study \\
\hline 171 & 162,211 & $5,599,143$ & 68.2 & 74,243 & SRR4096823 & This study \\
\hline 338 & 234,522 & $5,668,144$ & 67.7 & 60,032 & SRR4096824 & This study \\
\hline 244 & 140,427 & $5,575,105$ & 68.3 & 47,637 & SRR4096825 & This study \\
\hline 1 & $5,470,205$ & $5,470,205$ & 68.6 & $5,470,205$ & SRR4096850 & This study \\
\hline $\mathrm{n} / \mathrm{a}$ & $\mathrm{n} / \mathrm{a}$ & $\mathrm{n} / \mathrm{a}$ & $\mathrm{n} / \mathrm{a}$ & $\mathrm{n} / \mathrm{a}$ & $\mathrm{n} / \mathrm{a}$ & Giordano et al. 2012 \\
\hline $\mathrm{n} / \mathrm{a}$ & $\mathrm{n} / \mathrm{a}$ & $\mathrm{n} / \mathrm{a}$ & $\mathrm{n} / \mathrm{a}$ & $\mathrm{n} / \mathrm{a}$ & $\mathrm{n} / \mathrm{a}$ & Giordano et al. 2012 \\
\hline $\mathrm{n} / \mathrm{a}$ & $\mathrm{n} / \mathrm{a}$ & $\mathrm{n} / \mathrm{a}$ & $\mathrm{n} / \mathrm{a}$ & $\mathrm{n} / \mathrm{a}$ & $\mathrm{n} / \mathrm{a}$ & Giordano et al. 2012 \\
\hline $\mathrm{n} / \mathrm{a}$ & $\mathrm{n} / \mathrm{a}$ & $\mathrm{n} / \mathrm{a}$ & $\mathrm{n} / \mathrm{a}$ & $\mathrm{n} / \mathrm{a}$ & $\mathrm{n} / \mathrm{a}$ & Giordano et al. 2012 \\
\hline $\mathrm{n} / \mathrm{a}$ & $\mathrm{n} / \mathrm{a}$ & $\mathrm{n} / \mathrm{a}$ & $\mathrm{n} / \mathrm{a}$ & $\mathrm{n} / \mathrm{a}$ & $\mathrm{n} / \mathrm{a}$ & This study \\
\hline $\mathrm{n} / \mathrm{a}$ & $\mathrm{n} / \mathrm{a}$ & $\mathrm{n} / \mathrm{a}$ & $\mathrm{n} / \mathrm{a}$ & $\mathrm{n} / \mathrm{a}$ & $\mathrm{n} / \mathrm{a}$ & This study \\
\hline $\mathrm{n} / \mathrm{a}$ & $\mathrm{n} / \mathrm{a}$ & $\mathrm{n} / \mathrm{a}$ & $\mathrm{n} / \mathrm{a}$ & $\mathrm{n} / \mathrm{a}$ & $\mathrm{n} / \mathrm{a}$ & Giordano et al. 2012 \\
\hline $\mathrm{n} / \mathrm{a}$ & $\mathrm{n} / \mathrm{a}$ & $\mathrm{n} / \mathrm{a}$ & $\mathrm{n} / \mathrm{a}$ & $\mathrm{n} / \mathrm{a}$ & $\mathrm{n} / \mathrm{a}$ & Giordano et al. 2012 \\
\hline $\mathrm{n} / \mathrm{a}$ & $\mathrm{n} / \mathrm{a}$ & $\mathrm{n} / \mathrm{a}$ & $\mathrm{n} / \mathrm{a}$ & $\mathrm{n} / \mathrm{a}$ & $\mathrm{n} / \mathrm{a}$ & Giordano et al. 2012 \\
\hline $\mathrm{n} / \mathrm{a}$ & $\mathrm{n} / \mathrm{a}$ & $\mathrm{n} / \mathrm{a}$ & $\mathrm{n} / \mathrm{a}$ & $\mathrm{n} / \mathrm{a}$ & $\mathrm{n} / \mathrm{a}$ & Giordano et al. 2012 \\
\hline $\mathrm{n} / \mathrm{a}$ & $\mathrm{n} / \mathrm{a}$ & $\mathrm{n} / \mathrm{a}$ & $\mathrm{n} / \mathrm{a}$ & $\mathrm{n} / \mathrm{a}$ & $\mathrm{n} / \mathrm{a}$ & Giordano et al. 2012 \\
\hline $\mathrm{n} / \mathrm{a}$ & $\mathrm{n} / \mathrm{a}$ & $\mathrm{n} / \mathrm{a}$ & $\mathrm{n} / \mathrm{a}$ & $\mathrm{n} / \mathrm{a}$ & $\mathrm{n} / \mathrm{a}$ & This study \\
\hline $\mathrm{n} / \mathrm{a}$ & $\mathrm{n} / \mathrm{a}$ & $\mathrm{n} / \mathrm{a}$ & $\mathrm{n} / \mathrm{a}$ & $\mathrm{n} / \mathrm{a}$ & $\mathrm{n} / \mathrm{a}$ & This study \\
\hline $\mathrm{n} / \mathrm{a}$ & $\mathrm{n} / \mathrm{a}$ & $\mathrm{n} / \mathrm{a}$ & $\mathrm{n} / \mathrm{a}$ & $\mathrm{n} / \mathrm{a}$ & $\mathrm{n} / \mathrm{a}$ & This study \\
\hline 424 & 157,587 & $5,335,484$ & 68.5 & 25,071 & SRR4096817 & This study \\
\hline 1 & $5,751,786$ & $5,751,786$ & 68.6 & $5,751,786$ & SRR4096818 & This study \\
\hline 208 & 166,632 & $5,224,194$ & 68.8 & 60,802 & SRR4096851 & This study \\
\hline 488 & 89,429 & $5,563,628$ & 68.4 & 23,751 & SRR4096852 & This study \\
\hline 1 & $5,482,170$ & $5,482,170$ & 68.8 & $5,482,170$ & NC_015138 & Unpublished $^{\mathrm{d}}$ \\
\hline 1 & $5,354,379$ & $5,354,379$ & 68.5 & $5,354,379$ & NC_0 008752 & Unpublished $^{\mathrm{e}}$ \\
\hline $\mathrm{n} / \mathrm{a}$ & $\mathrm{n} / \mathrm{a}$ & $\mathrm{n} / \mathrm{a}$ & $\mathrm{n} / \mathrm{a}$ & $\mathrm{n} / \mathrm{a}$ & $\mathrm{n} / \mathrm{a}$ & PAMDB $^{\mathrm{f}}$ \\
\hline $\mathrm{n} / \mathrm{a}$ & $\mathrm{n} / \mathrm{a}$ & $\mathrm{n} / \mathrm{a}$ & $\mathrm{n} / \mathrm{a}$ & $\mathrm{n} / \mathrm{a}$ & $\mathrm{n} / \mathrm{a}$ & PAMDB \\
\hline $\mathrm{n} / \mathrm{a}$ & $\mathrm{n} / \mathrm{a}$ & $\mathrm{n} / \mathrm{a}$ & $\mathrm{n} / \mathrm{a}$ & $\mathrm{n} / \mathrm{a}$ & $\mathrm{n} / \mathrm{a}$ & PAMDB \\
\hline $\mathrm{n} / \mathrm{a}$ & $\mathrm{n} / \mathrm{a}$ & $\mathrm{n} / \mathrm{a}$ & $\mathrm{n} / \mathrm{a}$ & $\mathrm{n} / \mathrm{a}$ & $\mathrm{n} / \mathrm{a}$ & PAMDB \\
\hline $\mathrm{n} / \mathrm{a}$ & $\mathrm{n} / \mathrm{a}$ & $\mathrm{n} / \mathrm{a}$ & $\mathrm{n} / \mathrm{a}$ & $\mathrm{n} / \mathrm{a}$ & $\mathrm{n} / \mathrm{a}$ & PAMDB \\
\hline $\mathrm{n} / \mathrm{a}$ & $\mathrm{n} / \mathrm{a}$ & $\mathrm{n} / \mathrm{a}$ & $\mathrm{n} / \mathrm{a}$ & $\mathrm{n} / \mathrm{a}$ & $\mathrm{n} / \mathrm{a}$ & PAMDB \\
\hline $\mathrm{n} / \mathrm{a}$ & $\mathrm{n} / \mathrm{a}$ & $\mathrm{n} / \mathrm{a}$ & $\mathrm{n} / \mathrm{a}$ & $\mathrm{n} / \mathrm{a}$ & $\mathrm{n} / \mathrm{a}$ & PAMDB \\
\hline $\mathrm{n} / \mathrm{a}$ & $\mathrm{n} / \mathrm{a}$ & $\mathrm{n} / \mathrm{a}$ & $\mathrm{n} / \mathrm{a}$ & $\mathrm{n} / \mathrm{a}$ & $\mathrm{n} / \mathrm{a}$ & PAMDB \\
\hline $\mathrm{n} / \mathrm{a}$ & $\mathrm{n} / \mathrm{a}$ & $\mathrm{n} / \mathrm{a}$ & $\mathrm{n} / \mathrm{a}$ & $\mathrm{n} / \mathrm{a}$ & $\mathrm{n} / \mathrm{a}$ & $\mathrm{n} / \mathrm{a}$ \\
\hline $\mathrm{n} / \mathrm{a}$ & $\mathrm{n} / \mathrm{a}$ & $\mathrm{n} / \mathrm{a}$ & $\mathrm{n} / \mathrm{a}$ & $\mathrm{n} / \mathrm{a}$ & $\mathrm{n} / \mathrm{a}$ & $\mathrm{n} / \mathrm{a}$ \\
\hline $\mathrm{n} / \mathrm{a}$ & $\mathrm{n} / \mathrm{a}$ & $\mathrm{n} / \mathrm{a}$ & $\mathrm{n} / \mathrm{a}$ & $\mathrm{n} / \mathrm{a}$ & $\mathrm{n} / \mathrm{a}$ & $\mathrm{n} / \mathrm{a}$ \\
\hline $\mathrm{n} / \mathrm{a}$ & $\mathrm{n} / \mathrm{a}$ & $\mathrm{n} / \mathrm{a}$ & $\mathrm{n} / \mathrm{a}$ & $\mathrm{n} / \mathrm{a}$ & $\mathrm{n} / \mathrm{a}$ & $\mathrm{n} / \mathrm{a}$ \\
\hline
\end{tabular}

century. Acidovorax avenae was first described by Manns (1909) as the causal agent of leaf blight on oats in Ohio. In 1922, A. avenae was found to cause a similar disease on foxtail in Arkansas (Rosen 1922). Later A. avenae was commonly found as the causal agent of bacterial leaf blight of corn in the southern United States (Sumner and Schaad 1977). In Asia, A. avenae has caused bacterial leaf streak and bacterial brown stripe on rice (Kadota 1996; Shakya et al. 1985). Other sporadic infections caused by $A$. avenae in North America have also been observed on millet, barley, and sugarcane (Claflin et al. 1989; Elliott 1923; Gitaitis et al. 1978; Martin and Wismer 1989; Schaad et al. 2008). A single case of bacterial infection on creeping bentgrass caused by A. avenae (identified by $16 \mathrm{~s}$ rDNA sequencing) was reported in Fukuoka Prefecture, Japan in 2000 (Fuyuya et al. 2009). However, large-scale occurrence of BED on creeping bentgrass caused by $A$. avenae was never been reported prior to 2009. The emergence and spread of BED in North America is not well understood. Knowledge about origin and diversity of A. avenae are crucial to mitigate the spread of the disease in creeping bentgrass and may also help us to understand and prevent the emergence of other plant diseases. Management practices, including applying growth regulators and alleviating general stress of the grass with reduced mowing, have been shown effective in reducing the severity of this disease (Roberts et al. 2015, 2016).

In this study, we used comparative genomics approaches to characterize the first culture collection of the turfgrass pathogen $A$. avenae in North America. We provide evidence that the causal agents of BED on creeping bentgrass in the United States belong to two distinct phylogroups in the A. avenae species complex. Despite the genetic differences of the two pathogen lineages, the nucleotide sequences of a cluster of 11 genes located in the type III secretion system (T3SS) pathogenicity island are highly conserved in these two lineages. Finally, we provide evidence that recombination within the turfgrass $A$. avenae isolates played an important role during pathogen evolution. We demonstrate that the formation of the conserved T3SS sequences among turfgrass $A$. avenae isolates can be traced back to three recombination events. Together, our results allow us to propose a testable hypothesis about the evolution of host specificity in A. avenae. 


\section{RESULTS}

Turfgrass-pathogenic A. avenae strains

from the United States belong to two distinct phylogroups.

Between 2009 and 2012, 28 isolates of A. avenae were collected from creeping bentgrass with BED symptoms on golf courses across the United States (Table 1). Strains included in this study were collected from 15 states in the southeast, midAtlantic, midwest, Gulf coast, and northwest regions of the United States (Table 1). To understand the relationship of turfgrasspathogenic A. avenae to other species in the Acidovorax genus, we also included a selection of other plant-pathogenic members.

We first inferred a phylogenetic tree of the newly identified turfgrass-pathogenic A. avenae isolates to other closely related members of genus Acidovorax with a seven-gene multilocus sequence analysis (MLSA). Two methods, the maximum likelihood (ML) and Bayesian method of phylogenetic inference, produced a phylogentic tree with identical topology (Fig. 1). While some nodes are not well supported by the bootstrap values in the ML tree, they are strongly supported by high posterior probability values in the Bayesian tree (Fig. 1). The phylogeny showed that the turfgrass-pathogenic $A$. avenae strains are not monophyletic but fall into two distinct phylogroups (turfgrass groups 1 and 2) (Fig. 1). Each turfgrass phylogroup is more closely related to strains pathogenic to other monocot hosts (such as maize or rice) than to the other turfgrass phylogroup.

\section{BED disease in turfgrass is caused by a set of highly diverse bacterial strains.}

Seven turfgrass group 1 isolates, seven turfgrass group 2 isolates, three maize isolates, and one orchid isolate were selected for genome sequencing. Fifteen high-quality draft genomes and three complete genomes were generated (Table 1). We first determined the population diversity of the turfgrass A. avenae isolates. We identified a total of 165,645 single nucleotide polymorphisms (SNPs) across a total alignment length of 3,154,840 bp (avg. pairwise identity $=98.1 \%$ ) in a whole-genome alignment of 14 turfgrass genomes. The overall diversity of the 14 turfgrass A. avenae genomes was 0.0279 , as determined by Watterson's theta (Watterson 1975), about three times higher than the value observed in the kiwifruit pathogen Pseudomonas syringae pv. actinidiae (Watterson's theta $=0.008)$ (McCann et al. 2013). Interestingly, although the Acidovorax strains are more diverse than the $P$. syringae pv. actinidiae strains, genome rearrangements are less common. The A. avenae strains display a high level of synteny with significantly fewer translocations and
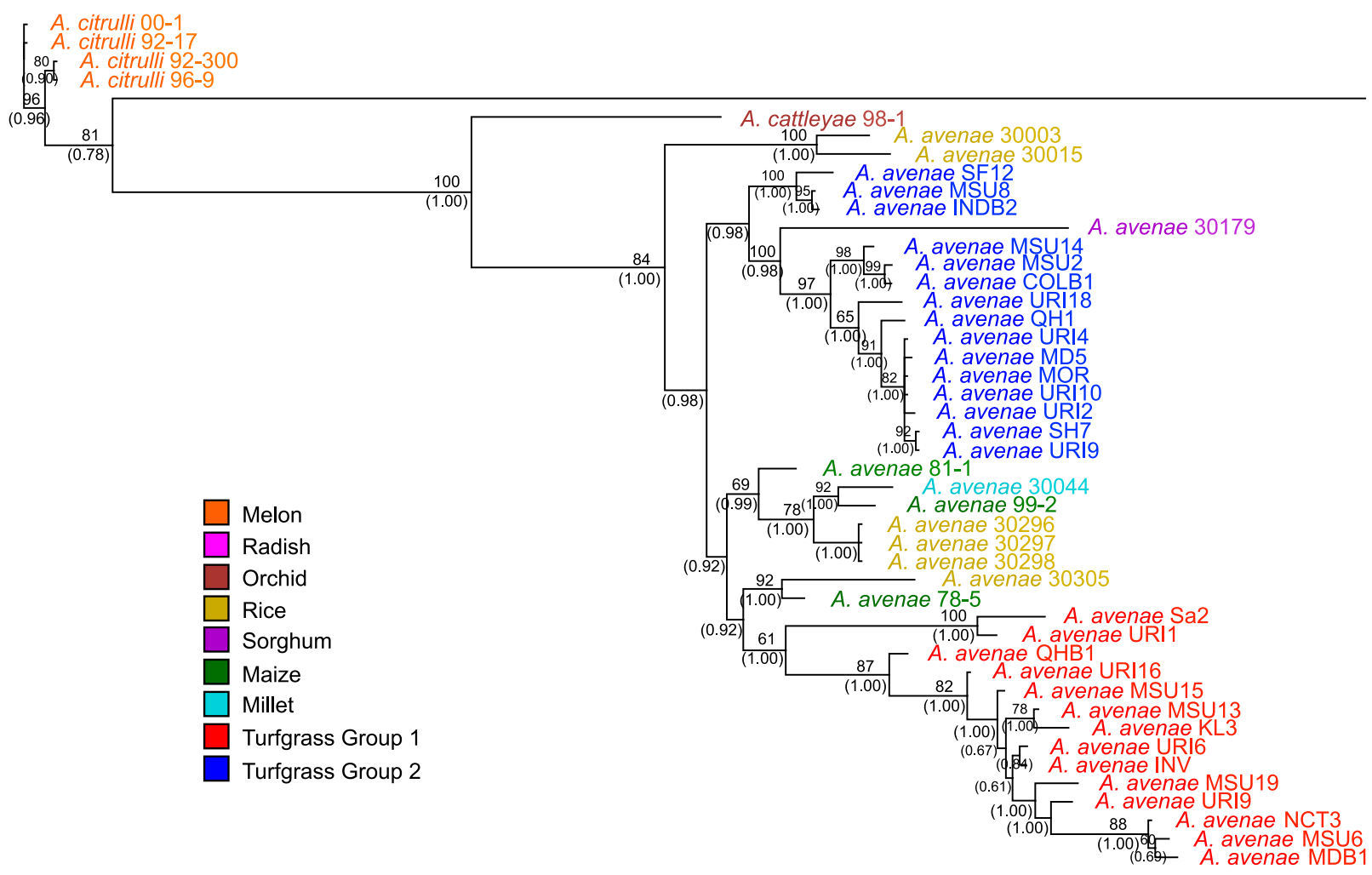

0.02

Fig. 1. Phylogeny of Acidovorax strains pathogenic to turfgrass and other plant hosts, inferred by multilocus sequence analysis. A phylogenetic tree generated from a seven-gene concatenated nucleotide sequence alignment using maximum likelihood (ML) with a general time reversible (GTR) model. A 50\% cutoff was used to create the bootstrap consensus tree, and bootstrap support values greater than $60 \%$ are indicated at each node. The same alignment was also used in a Bayesian method of phylogenetic inference analysis, which generated a converged tree with the same topology as the ML-GTR method. Numbers in parentheses indicate posterior probabilities. Colors indicate hosts of origin.

Table 2. Genome rearrangement events between maize strain AA81-1 and turfgrass strains MD5 and URI9

\begin{tabular}{lccccc}
\hline & Total SNPs $^{\mathbf{a}}$ & Breakpoints & Translocations & Inversions & Insertions/deletions \\
\hline AA81-1:MD5 & 123,743 & 880 & 67 & 12 & 407 \\
AA81-1:URI9 & 174,727 & 998 & 54 & 10 & 456 \\
MD5:URI9 & 157,075 & 1,042 & 68 & & 14 \\
\hline
\end{tabular}

${ }^{\text {a }}$ SNPs = single nucleotide polymorphisms. 
inversions, which indicates lower rates of recombination between and within strains in A. avenae (Table 2, Supplementary Fig. S1). Together, these results suggest that BED pathogen strains isolated between 2009 and 2012 are highly divergent (about half of that previously observed for Escherichia coli [Touchon et al. 2009; Bertels et al. 2014]) but, comparatively, have not been affected much by recombination.

The phylogeny of the 20 representative Acidovorax strains was also inferred, based on the SNPs identified at the genome level (Bertels et al. 2014). Consistent with the phylogeny from the seven-gene MLSA analysis, the whole-genome phylogenetic tree also grouped most turfgrass $A$. avenae strains into two phylogroups (Fig. 2, turfgrass groups 1 and 2). Sa2, which grouped with turfgrass group 1 in the MLSA tree (Fig. 1), was grouped separately in the whole-genome phylogenetic tree (Fig. 2). Furthermore, the nodes that are not well-supported (low bootstrap values) in the MLSA phylogeny (Fig. 1) are supported by high bootstrap values in the whole genome phylogeny (Fig. 2).

\section{Geographical distribution of turfgrass $A$. avenae strains.}

To test whether the phylogenetic relationships are shaped by geography, we also measured the distances between isolates and correlated them with genetic distances. Figure 3 shows that there are no significant correlations between genetic distance and geographic distance, which suggests that dispersal rates of $A$. avenae are too high to maintain spatially structured populations.

\section{Turfgrass and maize A. avenae isolates display host specificity and preference.}

Although the turfgrass-pathogenic A. avenae and maizepathogenic $A$. avenae were isolated from two different hosts, these two groups of pathogens are genetically closely related. To determine if the turfgrass and maize $A$. avenae strains exhibit host specificity, we compared the virulence of turfgrass and maize A. avenae strains on maize and creeping bentgrass. When inoculated on maize, maize A. avenae strains display a strong virulence phenotype, whereas the turfgrass strains we tested (from both group 1 and group 2) are nonpathogenic to maize (Supplementary Fig. S2). Host specificity is also supported by our pathogen population assays, which show that maize isolates establish significantly larger populations than turfgrass strains when inoculated on maize (Fig. 4A). Conversely, on turfgrass, both turfgrass $A$. avenae and maize $A$. avenae can cause some necrosis and plant death (Fig. 4B) but the disease symptom is much more severe on turfgrass inoculated with turfgrass $A$. avenae than the ones inoculated with maize A. avenae. Additionally, turfgrass $A$. avenae strains establish significantly larger populations on turfgrass (Fig. 4A) and caused more plant death (Fig. 4B) compared with maize A. avenae strains. Together, these analyses show that turfgrass A. avenae and maize A. avenae specifically and preferentially infect the original hosts they were isolated from.

The two phylogroups of turfgrass $A$. avenae contain conserved sequences in the T3SS pathogenicity island.

Despite the significant divergence of the two turfgrass $A$. avenae phylogroups, both groups showed high specificity at infecting turfgrass. To identify a genetic cause for this specificity, we performed a genome-wide search for genes that are more closely related within turfgrass-infecting A. avenae than they are to their homologs in the maize-pathogenic strains. Nucleotide sequence alignments of 4,179 genes were individually generated and were used to infer the phylogeny of the turfgrass and maize isolates. Of the 4,179 trees, 26 grouped the two turfgrass phylogroups and the turfgrass-infecting $\mathrm{Sa} 2$ strain together, separate from the maize phylogroup (Figure 5 shows four examples and the full list of phylogenetic trees is available in Supplementary Figure S3). The identified genes encode functions such as virulence, chemotaxis, iron transportation, metabolism, and unknown functions (Table 3). Interestingly, 11 of these genes are located in the T3SS pathogenicity island as a gene cluster (Fig. 6B). The fact that the two distantly related phylogroups of turfgrass A. avenae both share high sequence similarity

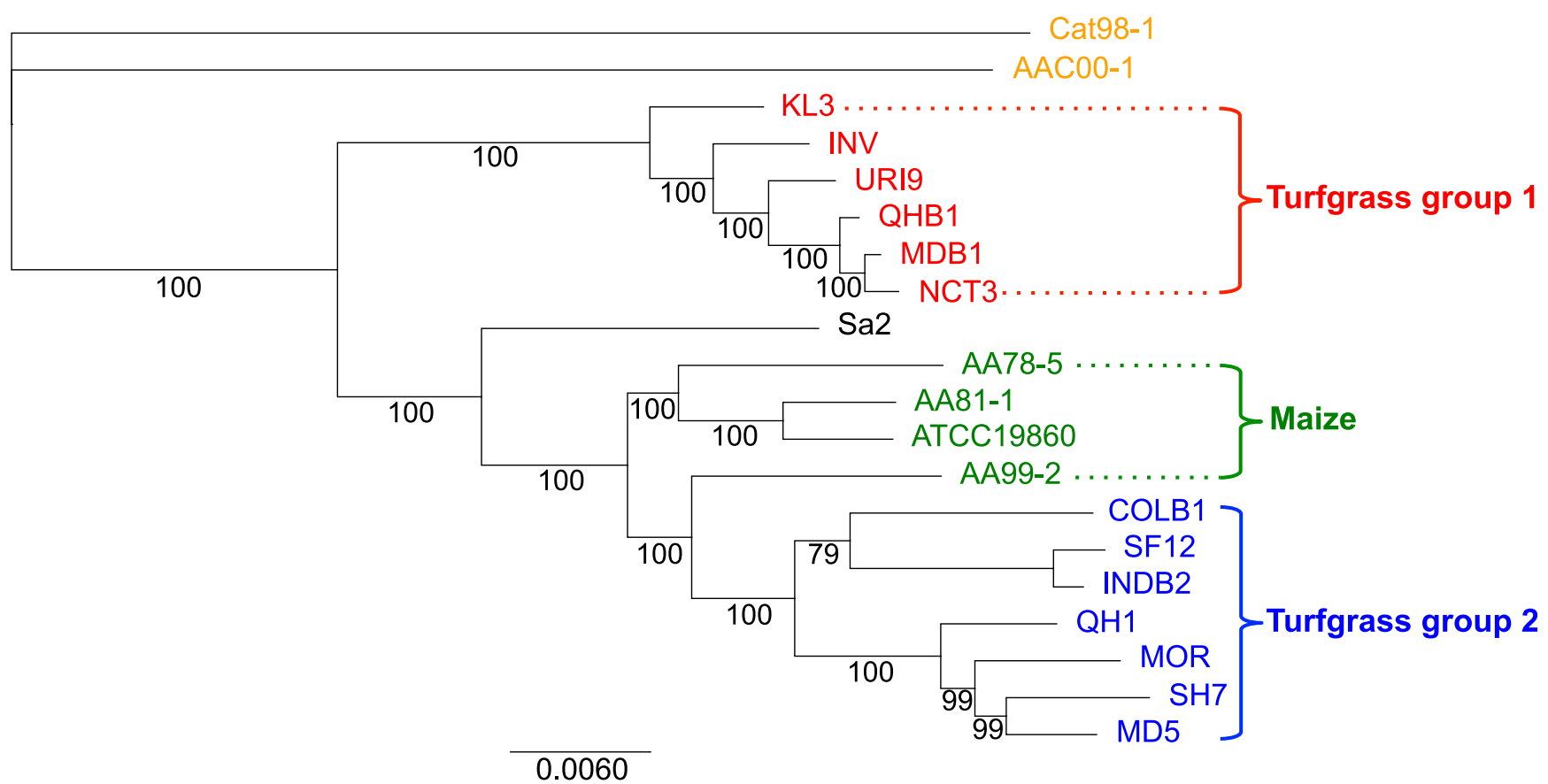

Fig. 2. Phylogeny of Acidovorax strains, inferred from a whole-genome alignment. The phylogenetic tree was generated using a merged whole-genome alignment generated by REALPHY. The merged tree was rooted using Cat98-1 and AAC00-1 as outgroups. A 50\% cutoff was used to create the bootstrap consensus tree, and bootstrap support values greater than $60 \%$ are indicated at each node. Turfgrass pathogenic A. avenae strains were grouped into two phylogroups (turfgrass groups 1 and 2) with the exception of $\mathrm{Sa} 2$. 
in this virulence-related gene cluster suggests that these genes may contribute to host specificity in A. avenae.

To further define the sequence conservation in the T3SS pathogenicity island, we generated a $32-\mathrm{kb}$ nucleotide alignment of 34 genes in the T3SS pathogenicity island (Acav_0510Acav_0543) from four maize and 14 turfgrass A. avenae strains. Within the alignment, one region showed a particularly low genetic variability (approximately 17,500 to 27,500 bp) (Fig. 6C). This region completely overlaps with the location of the 11 host-specific genes identified with our phylogenetic method (Fig. $6 \mathrm{~B}$, highlighted in green).

\section{Recombination occurred between the two turfgrass} phylogroups but not between the turfgrass phylogroups and the maize phylogroup.

The clustering of turfgrass-infecting A. avenae strains in the T3SS pathogenicity island in turfgrass $A$. avenae could be caused by various mechanisms; however, recombination seems to be the most likely. To test for recombination, we applied a Phi test (Bruen et al. 2006) to a total of six A. avenae genomes (two group 1 turfgrass strains, INV and NCT3, two group 2 turfgrass strains, QH1 and SF12, and two maize strains, AA78-5 and AA81-1), which predicts high recombination rates between these genomes with significant statistical support $(P<0.0001)$. To determine the extent and the exact location of the recombination events in turfgrass and maize A. avenae strains, we applied GENECONV (Sawyer 1989). In turfgrass strains, high levels of gene conversion were detected between strains of the same phylogroup (Fig. 7A, boxes 1 and 2) and moderate levels of recombination were detected between strains of different phylogroups (Fig. 7A, box 4). Interestingly, almost no gene conversion was detected between turfgrass strains and maize strains (Fig. 7A, boxes 5 and 6). These observations suggest that very limited genetic exchange occurred between the turfgrass

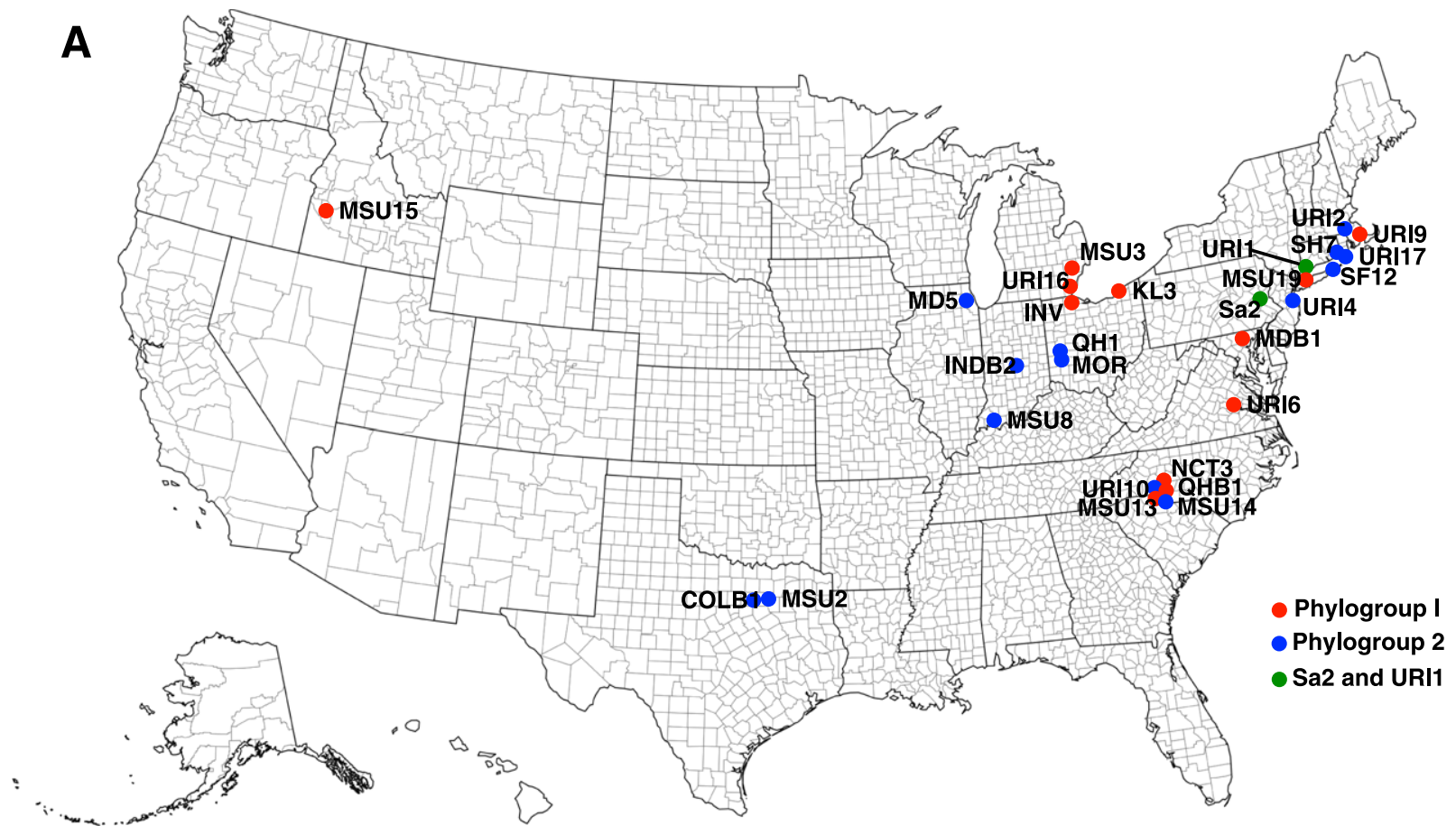

B

Spearman correlation

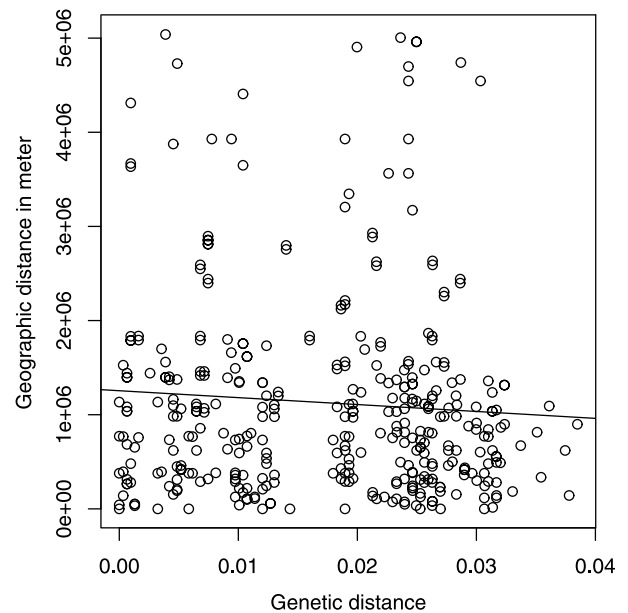

Mantel's test

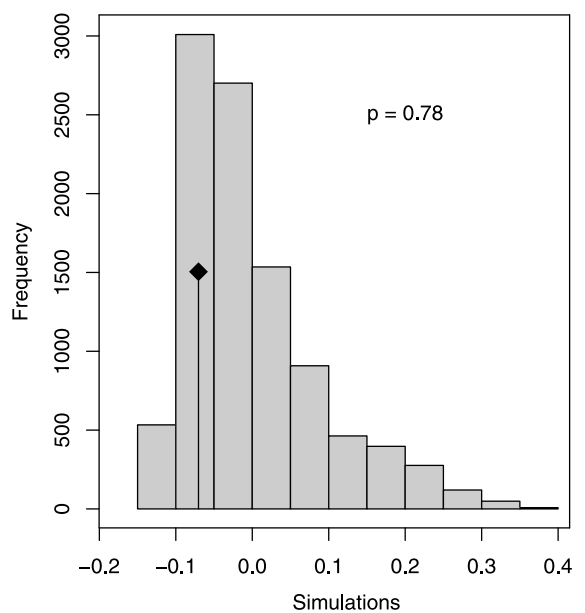

Fig. 3. Geographical distribution and genetic correlation of the turfgrass A. avenae strains. A, Geographical distribution of the turfgrass A. avenae strains by phylogroups in the United States. B, Matrix of geographical distance and genetic distance of the mapped strains, generated by Mantel's test. 
isolates and maize isolates; however, significant amounts of genetic exchange occurred within the turfgrass-specific A. avenae populations, both within and across the two phylogroups.

We also determined the level of recombination in the T3SS pathogenicity island in turfgrass and maize strains (Fig. 7B). Similar to the results from the whole-genome analysis, limited gene conversion was detected between turfgrass and maize isolates in the T3SS pathogenicity island (Fig. 7B, boxes 5 and 6), whereas higher levels of gene conversion were detected among turfgrass isolates (Fig. 7B, boxes 1, 2, and 4). Interestingly, across-group recombination (group 1-group 2, group 1-Sa2, and group 2-Sa2) occurred at a much higher level on the T3SS pathogenicity island (Fig. 7B, box 4) than that of the whole genome (Fig. 7A, box 4). Alignment of the gene conversion fragments to the T3SS pathogenicity island revealed that most of the crossgroup gene conversion (Fig. 6A, magenta lines) occurred in the region of the identified host-specific genes $(16,000$ to $27,000 \mathrm{bp}$ ) (Fig. 6B, ORFs highlighted in green). Together, our results suggest that recombination between the two turfgrass phylogroups has played an important role for the evolution of host specificity in turfgrass $A$. avenae.

\section{Three recombination events can explain the observed T3SS phylogeny.}

Our analyses suggest that recombination is a likely cause for the high sequence conservation of T3SS genes among turfgrassinfecting $A$. avenae strains. To infer a likely time frame for when the recombination occurred, we generated a nucleotide alignment of the host-specific T3SS genes (Acav_0525 to Acav_0536). The inferred phylogeny (Fig. 8A) is consistent with the whole-genome phylogeny (Fig. 8B) within both turfgrass phylogroups with two exceptions: URI9, a strain that is listed as a group 1 turfgrass strain in the whole-genome phylogeny (Fig. 8B), is now grouped with group 2 turfgrass strains in the T3SS host-specific phylogeny (Fig. $8 \mathrm{~A}$ ), and $\mathrm{Sa} 2$, a strain that is listed as a single clade separate from the group 1 and group 2 turfgrass strains (Fig. 8B), is now grouped with group 1 strains in the T3SS host-specific phylogeny (Fig. 8A). Hence, we can explain the difference between the hostspecific T3SS tree and the whole-genome phylogeny with only three recombination events: one recombination occurred between the ancestor of group 1 turfgrass and the ancestor group 2 turfgrass strains, the second recombination event occurred between URI9 and the ancestor of INDB2 and SF12, and the third recombination event occurred between Sa2 and the ancestor of QHB1, MDB1, and NCT3 (Fig. 8B).

As these recombination events may have occurred a long time ago, the low genetic variation of the Acav_0525-Acav_0536 region is likely due to strong purifying selection acting to preserve sequence identity. To test this hypothesis, the ratios of nonsynonymous to synonymous substitutions $(\mathrm{dN} / \mathrm{dS})$ of genes located in the T3SS pathogenicity island were measured in group 1 and group 2 turfgrass A. avenae strains (KL3, INV, URI9, QHB1, NCT3, COLB1, SF12, INDB2, QH1, MOR, $\mathrm{SH} 7$, and MD5). Of all 33 genes in the T3SS pathogenicity island, 17 genes were detected to be under purifying selection (Table $4, \mathrm{dN} / \mathrm{dS}<1, P<0.01$ ). However, genes under purifying selection are concentrated at the first $10-\mathrm{kb}$ of the T3SS pathogenicity island and mostly encode for the T3SS structure and regulation (Table 4, Acav_0510-Acav_0519). Within the 11 genes in the host-specific region (Acav_0525-Acav_0536), only three genes (Acav_0525, Acav_0527, and Acav_0531) were affected by purifying selection with statistical significance (Table 4). However, when inspecting the data closely, it is obvious that the high $P$ values are not due to $\mathrm{dN} / \mathrm{dS}$ values that are indistinguishable from 1 , because there are $\mathrm{dN} / \mathrm{dS}$ values that are 0 (the lowest possible value) but still not significantly different from 1 . Hence, low significance is due to the fact that genetic variation in this part of the genome is too low (Table 4, piDn and piDs values) to sample enough substitutions to allow for accurate $\mathrm{dN} / \mathrm{dS}$ measures. This indicates that $\mathrm{dN} / \mathrm{dS}$ is not an appropriate measure to gauge selection strength across the host-specific T3SS region.

\section{Relative sequence diversity as a measure of selection.}

Alternatively, we can determine relative sequence diversity as a measure of purifying selection. Sequence diversity can be low either because selection acts to reduce diversity (every mutation has a lower fitness than any new mutation) or because
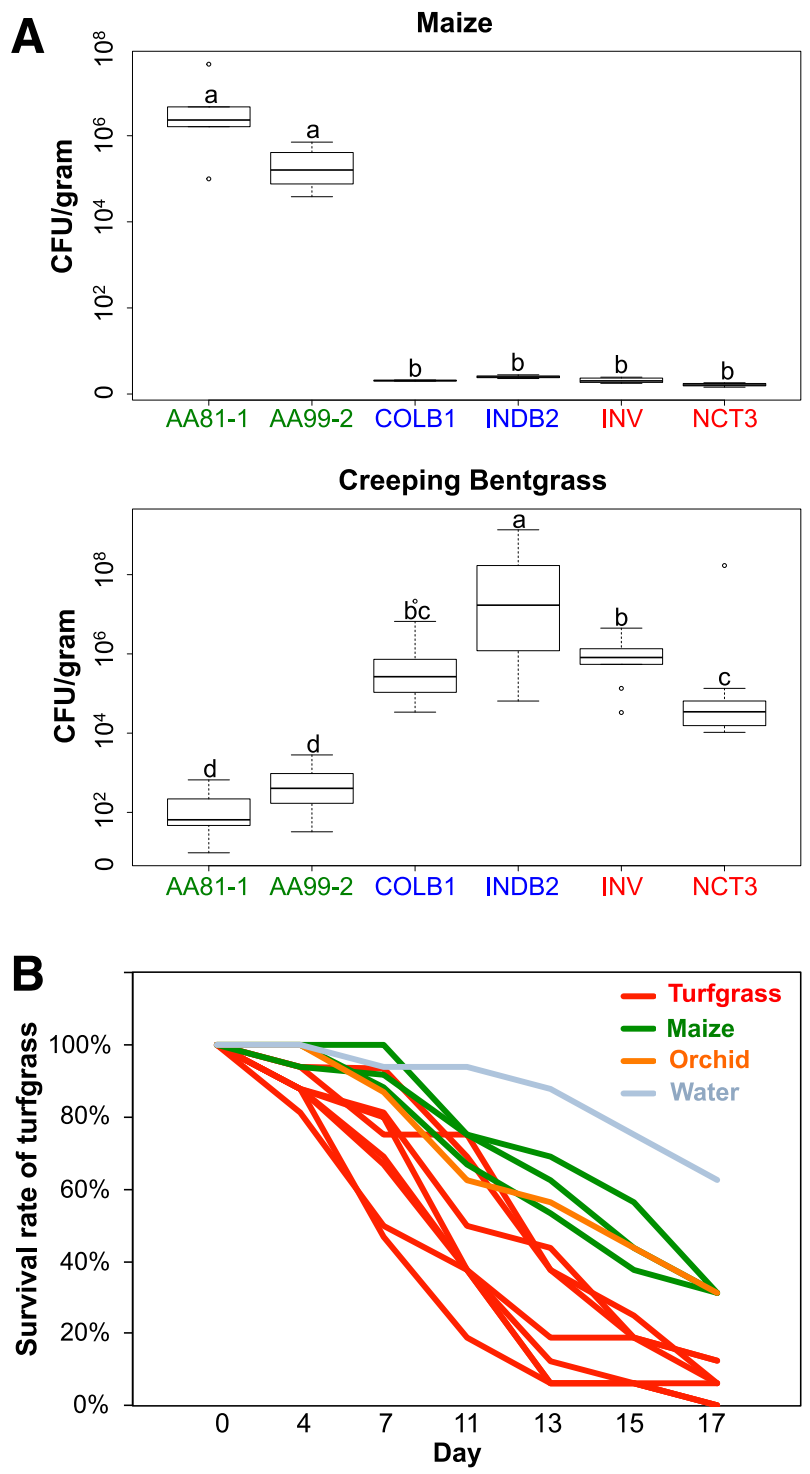

Fig. 4. Virulence of the turfgrass and maize Acidovorax avenae strains on maize and turfgrass. A, Population of different A. avenae strains inoculated on maize (Zea mays 'Peach Cream') and creeping bentgrass (Agrostis stolonifera 'PenA4'). Inoculation of maize was performed by cutting the tip of the second expanded leaf off across the veins, using an overnight culture adjusted to $10^{8}$ $\mathrm{CFU} \mathrm{ml}{ }^{-1}$. Inoculation of turfgrass was performed by cutting the root of the surface-sterilized grass and maintaining the root of the grass in a bacterial suspension of $10^{8} \mathrm{CFU} \mathrm{ml}{ }^{-1}$. The inoculated maize and turfgrass plants were maintained at 26 and $22^{\circ} \mathrm{C}$ (day and night, respectively) and $80 \%$ humidity and at $32^{\circ} \mathrm{C}, 80 \%$ humidity, respectively. The internal pathogen population was sampled by plating at $72 \mathrm{~h}$ postinoculation. Strains are color coded by their phylogroups (green: maize, red: turfgrass group 1, blue: turfgrass group 2). Statistical analysis was performed using analysis of variance with $\alpha=$ 0.05 . The level of significance was calculated using LSD $(\alpha=0.05)$. B, Survival rate of creeping bentgrass 'PennA4' after inoculation of turfgrass and maize-pathogenic A. avenae strains. The experiment was repeated two times and data from one experiment is presented in this figure. 
the rest of the genome is under positive selection and our region of interest is evolving neutrally (or under less positive selection pressure). Either way the selection on the host maintains the sequence identity in the host-specific T3SS region. To determine relative sequence diversity, we measured the Shannon entropy for each nucleotide across the T3SS pathogenicity island in the turfgrass strains. The host-specific region of the T3SS (16,000 to $25,000 \mathrm{bp}$ ) displayed a significantly lower nucleotide diversity compared with the rest of the genome (98\% of all 500-bp windows across the genome have higher nucleotide diversity than the turfgrass-specific region [Fig. 9B]). When compared with the diversity of the whole genome, both the T3SS pathogenicity island and the T3SS host-specific region display diversity values below the genome average, with the value in T3SS host-specific region ( $22 \%$ of the genome average) much lower than the entire T3SS (55\% of the genome average) (Fig. 9A). This observation strongly suggests purifying selection as the main driver of evolution for the T3SS pathogenicity island and especially for the T3SS host-specific region. In addition, one region, which aligns with hpaP (Acav_0517) within the T3SS, showed a significantly higher level of nucleotide diversity (195\% of the genome average [Fig. 9B]). This suggests that the T3SS pathogenicity island is also affected by diversifying selection in addition to the strong

Acav_0526

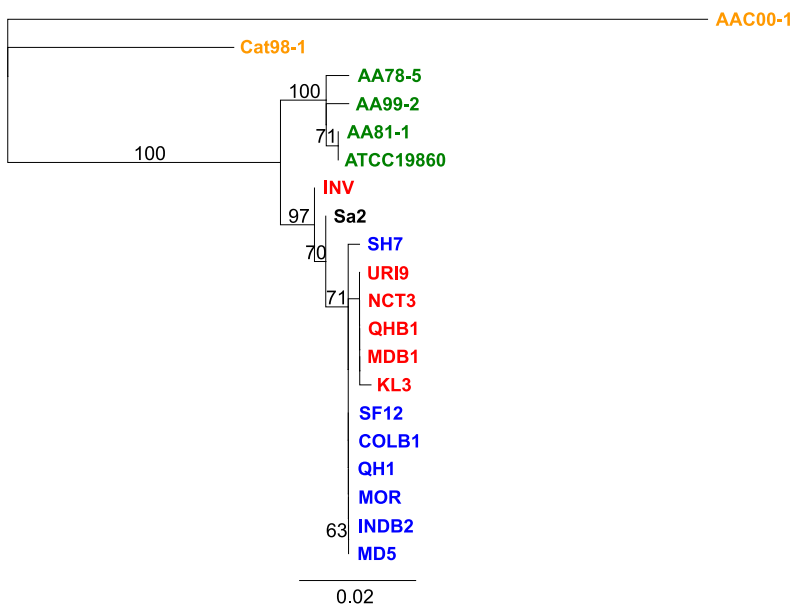

Acav_0528

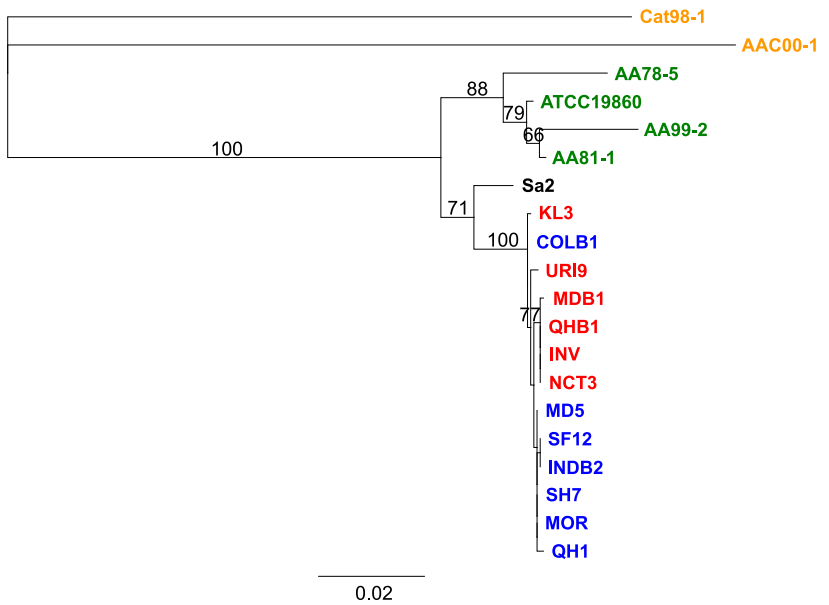

purifying selection of the host-specific region. Compared with the turfgrass strains, no significant purifying selection was observed in either the T3SS host-specific region or the T3SS pathogenicity island in maize strains (103 and 93\% of the genome average, respectively [Supplementary Fig. S4]).

\section{DISCUSSION}

In our study, we sequenced a set of 18 A. avenae strains, 14 of which were isolated from a recent BED outbreak on creeping bentgrass (turfgrass). We found that not only do the 14 strains not belong to the same clonal strain but that they form two major phylogroups within the A. avenae species (if not including the single strain $\mathrm{Sa} 2$, which is separately grouped as a single clade). It is unusual that a novel disease is caused by a diverse range of strains, as most disease outbreaks are caused by a highly virulent clonal plant pathogen (e.g., Xylella fastidiosa strains associated with olive quick decline syndrome in Italy and some of the phylotype II strains of Ralstonia solanacearum causing diseases on banana and potato [Ailloud et al. 2015; Marcelletti and Scortichini 2016]). Although BED in creeping bentgrass has not been described before, the strains causing the disease have not recently emerged but probably
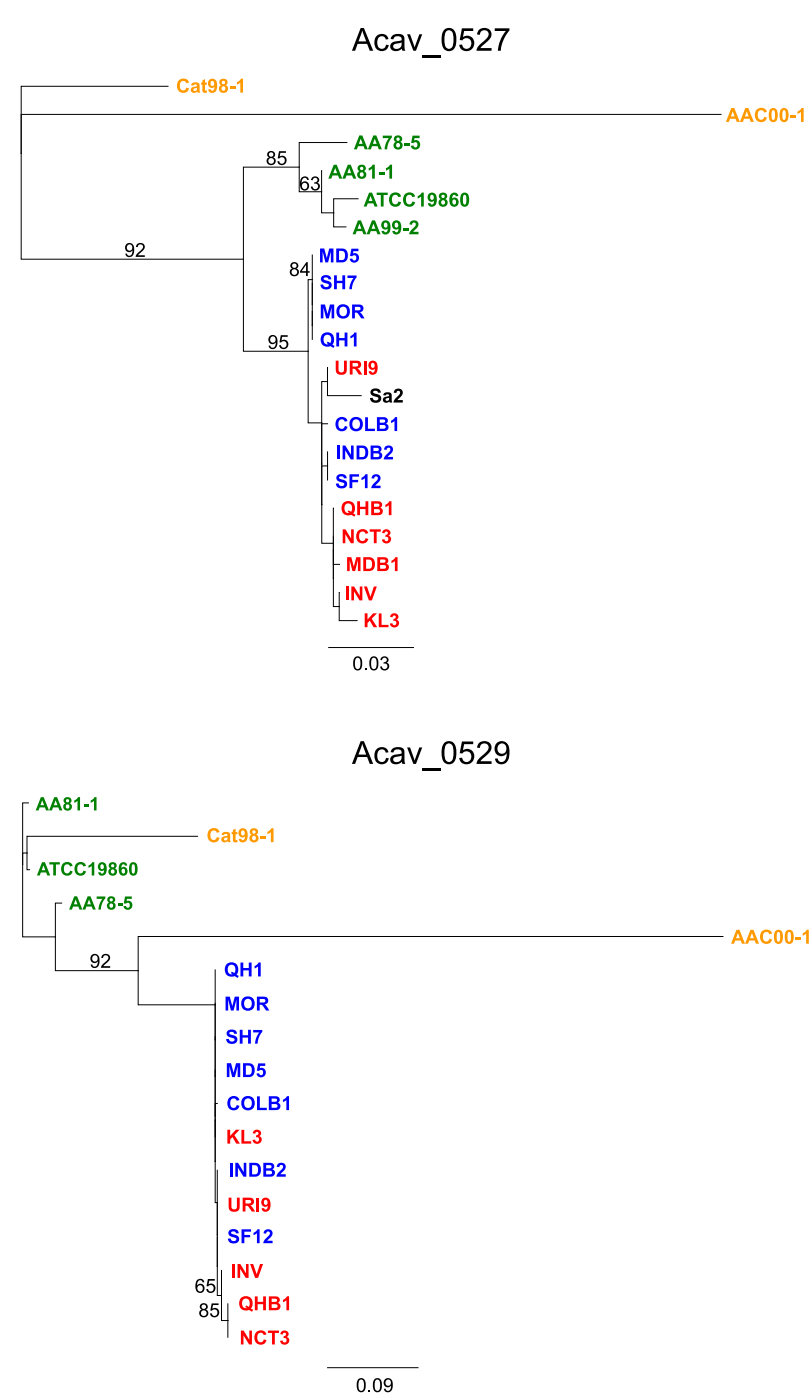

Fig. 5. Phylogeny of genes that group turfgrass-infecting Acidovorax avenae strains into a monophyletic group. The phylogeny of a selection of four genes in the type III secretion system pathogenicity island are displayed. The phylogeny was inferred using nucleotide sequence alignment of the individual genes by maximum likelihood with a general time reversible model and was color-coded by hosts and phylogroups (green: maize, red: turfgrass group 1, blue: turfgrass group 2, black: $\mathrm{Sa}$, yellow: outgroups). A $50 \%$ cutoff was used to create the bootstrap consensus tree, and bootstrap support values greater than $60 \%$ are indicated at each node. 
diverged millions of years ago, as our phylogenetic analyses and host-specificity assays show. Instead, it is more likely that the hot summers between 2009 and 2012 provided an optimal environment for $A$. avenae to thrive on creeping bentgrass, which probably resulted in more severe symptoms than usual. Alternatively, A. avenae strains could be adapting to creeping bentgrass and slowly increasing in virulence. However, this hypothesis seems less likely since such an adaptation would have to happen in parallel across very different strains and within the exact same time frame.

Although the BED outbreak between 2009 and 2012 displayed low virulence phenotypes, a severe outbreak may still occur as observed for the kiwifruit pathogen $P$. syringae pv. actinidiae, in which a highly pathogenic $P$. syringae pv. actinidiae clone emerged from a highly diverse set of related low-virulence $P$. syringae pv. actinidiae strains and spread worldwide within a few years (McCann et al. 2013). Hence, it is possible (and the high diversity and recent population expansion may even make it likely) that, from this population of strains, a highly virulent strain will emerge that can cause a devastating future outbreak.

We also showed that the high genetic diversity we observe between turfgrass strains was not correlated with their geographic origin. This suggests that dispersal rates of A. avenae are much higher than genetic diversification rates. At this point, it is unclear whether high dispersal rates are an effect of human activity or whether A. avenae is easily dispersed by wind, rain, seeds, or animals.

In laboratory experiments, we have shown that both $A$. avenae isolates from turfgrass and maize are host specific despite the distant relationship between some of the strains. This begs the question what determines host specificity in A. avenae. Two common mechanisms can explain bacteria gaining pathogenicity of a specific host, i.e., acquiring host-specific virulence genes through horizontal gene transfer or adaptation to generate hostspecific alleles (McCann and Guttman 2008).

We tested these hypotheses with extensive whole-genome sequence analyses and phylogenetic analyses. We first performed BLAST to search for putative virulence factors that are only present in turfgrass strains but not in maize strains. However, this effort did not identify any genes that may explain the host specificity in turfgrass. Although putative host-specificity or virulence genes including the T3 effectors vary significantly in their presence among strains (Supplementary Fig. S5), we could not find virulence factors that are present exclusively in turfgrass strains. However, as many of the genomes are draft genomes, we cannot exclude the possibility that some virulence genes are missing due to variations in sequencing depth that can cause erroneous assemblies. Next, we identified a cluster of genes in the T3SS that placed all turfgrass-infecting strains into a single monophyletic group. These turfgrass-infecting strains are from diverse phylogenetic backgrounds, including strains from two distinct phylogroups (group 1 and group 2) and a separately grouped strain (Sa2). The fact that the identified genes are highly conserved in diverse strains infecting the same host and that they are involved in virulence raises the possibility that this region is responsible for determining turfgrass-specific growth of $A$. avenae.

The 10-kb turfgrass-specific region we discovered in this study represents a significant portion of the T3SS pathogenicity island, accounting for about one third of the entire pathogenicity island. Genes in this region encode both putative T3 effectors, structural components of the secretion apparatus, and proteins with unknown functions. The T3SS in A. avenae has been poorly studied, and the functions of most genes in the T3SS pathogenicity island remain unvalidated or uncharacterized. Among the genes that are conserved in the T3SS pathogenicity island, four genes (lrp, Acav_0526, Acav_0527, and Acav_0528) were predicted to encode T3 secreted proteins (Table 3), which suggests that they are putative T3 effectors or harpin proteins. Although the functions of these genes are unknown, homolog search revealed that one of these four genes, lrp (Acav_0525), encodes a putative GalA like T3 effector (GalA1), which was previously shown to manipulate the host ubiquitin-proteasome system (Remigi et al. 2011). T3 effectors and harpins are at the front line of suppressing host immunity and promoting pathogenicity (Büttner and He 2009). Some have even been shown to be important determinants of host specificity (Baltrus et al. 2012). It is possible that the homologs in turfgrass-infecting A. avenae may grant the ability to evade host surveillance.

In addition to the $\mathrm{T} 3$ secreted proteins, we also identified three genes encoding components of the inner ring of the secretion apparatus ( $h r c N, h r c L$, and $h r c J)$. $h r c N$ encodes an ATPase located on the cytoplasm side of the inner membrane and $\mathrm{HrcL}$ and $\mathrm{HrcJ}$ are proteins associated with $\mathrm{HrcN}$. Previous reports showed that $\mathrm{HrcN}$ and other proteins located on the inner ring of the secretion apparatus are involved in the translocation of T3 effectors (Büttner and He 2009). Although the exact fitness advantage of maintaining a conserved inner membrane ring is not known, it is possible that the turfgrass A. avenae utilizes the conserved sequences on the inner membrane to mediate the translocation of host-specific T3 effectors and thus confer host specificity. The remaining putative hostspecific genes do not share homology with proteins of known function. Future experiments are needed to determine their role in pathogenicity and host specificity.

Sequence variations of T3 effector proteins causing variations in pathogenicity have been documented in previous studies (Stevens et al. 1998; Yang et al. 2005). For example, seven different natural allelic variants were identified in the T3 effector HopX in

Table 3. Genes that cluster all turfgrass-infecting Acidovorax avenae strains into a monophyletic group ${ }^{\mathrm{a}}$

\begin{tabular}{|c|c|c|}
\hline Genomes & $\begin{array}{l}\text { Gene } \\
\text { name }\end{array}$ & Predicted gene function \\
\hline Acav_0216 & & Hypothetical protein \\
\hline Acav_0303 & & Hypothetical protein \\
\hline Acav_0483 & & Chemotaxis methyl-accepting receptor \\
\hline Acav_0509 & & Chorismate mutase \\
\hline Acav_0525 b & lrp & $\begin{array}{l}\text { Putative GalA like T3 effector } \\
\text { (with leucine-rich repeat) }\end{array}$ \\
\hline Acav_0526 bc & & Hypothetical protein \\
\hline Acav_0527 c & & Hypothetical protein \\
\hline Acav_0528 ${ }^{\text {c }}$ & & Hypothetical protein \\
\hline Acav_0529 & & Hypothetical protein \\
\hline Acav_0530 & $\operatorname{hrcN}$ & T3S apparatus ATPase \\
\hline Acav_0531 & hrcL & T3S apparatus protein, HrpE/YscL \\
\hline Acav_0533 & hrcJ & YscJ/HrcJ family T3S apparatus lipoprotein \\
\hline Acav_0534 & hrpB2 & T3S protein HrpB2 \\
\hline Acav_0535 & hrpB1 & T3S protein HrpB1/HrpK \\
\hline Acav_0536 & & Hypothetical protein \\
\hline Acav_0715 & & Single subunit mitochondrial RNA polymerase \\
\hline Acav_0952 & & $S$-adenosylmethionine synthetase \\
\hline Acav_1526 & & $(2 \mathrm{Fe}-2 \mathrm{~S})$-binding domain-containing protein \\
\hline Acav_1813 & & Alcohol dehydrogenase \\
\hline Acav_2773 & isc $S$ & Cysteine desulfurase \\
\hline Acav_2826 & & Hypothetical protein \\
\hline Acav_2827 & estB & Phospholipase \\
\hline Acav_2829 & & Class I peptide chain release factor \\
\hline Acav_2839 & & $\mathrm{Fe}^{3+}$-transporting ATPase \\
\hline Acav_2853 & $c l s A$ & Cardiolipin synthetase \\
\hline Acav_3448 & & Flavin-containing monooxygenase-like protein \\
\hline
\end{tabular}

${ }^{a}$ Bold indicates genes in the type III secretion (T3S) system pathogenicity island.

b Putative T3S protein, predicted by Effective ELD (based on eukaryoticlike domains). Only predictions with high confidence was displayed. c Putative T3S protein, predicted by Effective T3 (based on the N-terminal signal peptide). 
P. syringae (Stevens et al. 1998). The wild-type allele of HopX induces the hypersensitive response in bean, while all other variants do not. In another study, host-adapted polymorphisms were found in multiple virulence-related genes (such as the T3 effector) in banana pathogenic and nonpathogenic Ralstonia solanacearum strains. The authors suggest that these polymorphisms may explain differences in host range (Ailloud et al. 2015). Although these examples establish the correlation between host-specific alleles and the corresponding phenotypes, the distribution of these host-specific alleles in natural pathogen populations, as well as the evolutionary mechanisms responsible for the formation of these alleles, are not well understood. In this study, we provide evidence that the conserved host-specific sequences could be shared in distantly related phylogroups of pathogens. We also showed that the host-specific alleles were formed by recombination and were preserved by purifying selection.

The evolutionary mechanisms that cause the observed allelic diversity are not very well understood; however, as we show in this study, recombination generally plays a major role
(Awadalla 2003; Baltrus et al. 2017; Menardo et al. 2016; Mhedbi-Hajri et al. 2013; Yan et al. 2008). Strains causing a disease outbreak often show signs of extensive recombination with related strains (McCann et al. 2013; Monteil et al. 2013). For instance, the $P$. syringae pv. actinidiae strain causing the 2008 kiwifruit outbreak displays significant levels of homologous recombination, about 8.3 and $21.4 \%$ of the NZ V-13 genome (one of the outbreak strains) arose from recombination with strains from Korea and Japan, respectively (McCann et al. 2013). In our study, we show that turfgrass-pathogenic A. avenae strains are also significantly affected by recombination; on average, $7.54 \%$ of the genome was affected by recombination when comparing any two turfgrass-pathogenic A. avenae strains (Fig. 7). Generally, it is difficult to determine the number of recombination events needed for divergent bacterial strains to infect a common host. Naively, one would assume that attaining host specificity is a long and complex multistep recombination process. In contrast, in our study, we demonstrate that as few as three recombination events may have been sufficient to enable divergent $A$. avenae to

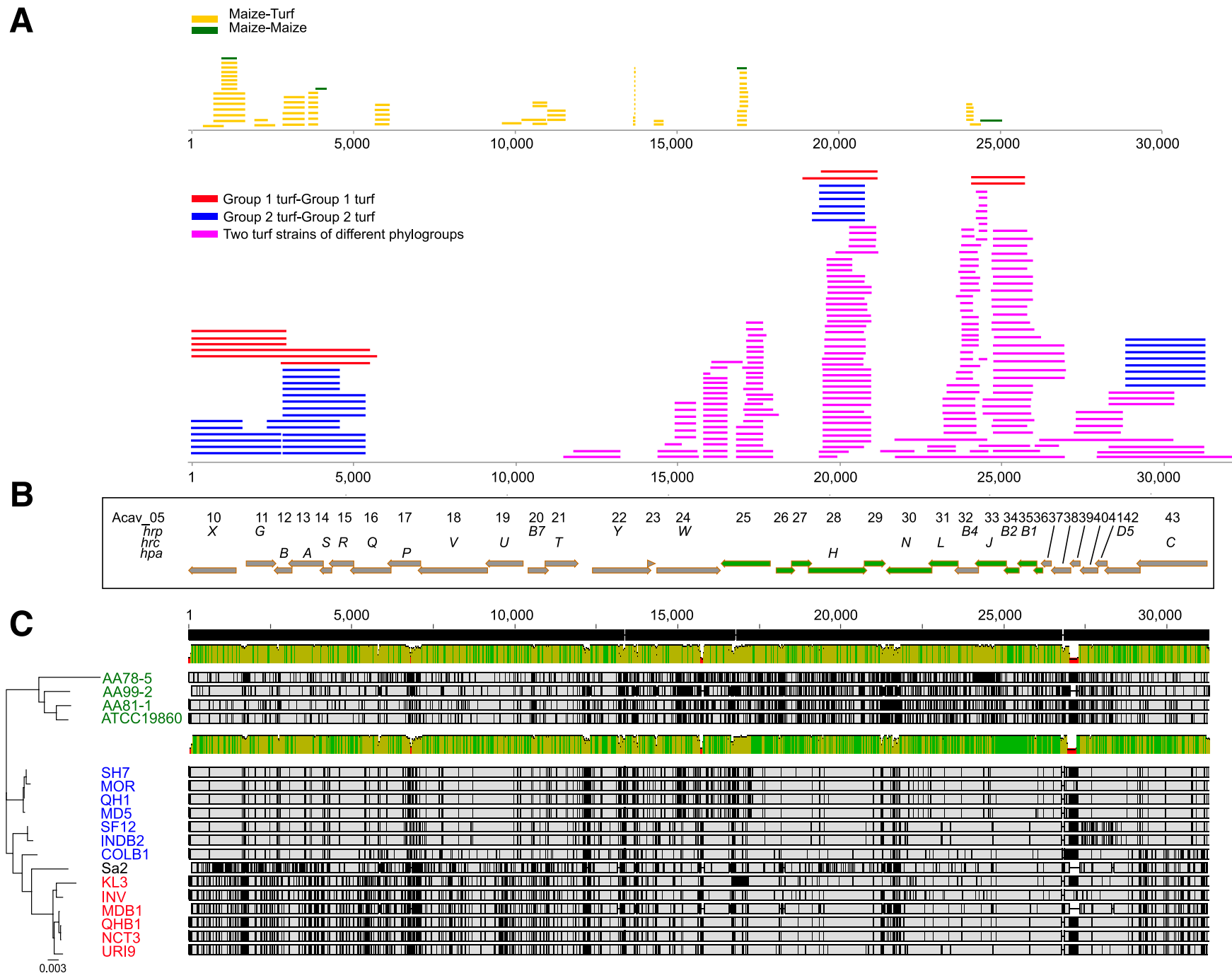

Fig. 6. Genetic variance and gene conversion fragments mapped to the type III secretion system (T3SS) pathogenicity island in turfgrass- and maize-infecting strains. A, Gene conversion fragments identified in the T3SS pathogenicity island. The gene conversion fragments between any two strains were identified by first aligning the nucleotide sequences of the T3SS pathogenicity islands and, then, using the T3SS nucleotide alignment as input in GENCONV to identify gene conversion fragments. The identified fragments were mapped back to the T3SS pathogenicity island and were color-coded by the identity of the two strains. B, Open reading frames (ORFs) in the T3SS pathogenicity island. Gene names and their corresponding identification code (Acav_0510-Acav_0543) are labeled above the ORFs. The green-colored ORFs are genes that place turfgrass-infecting strains into a monophyletic group. C, The alignment of the nucleotide sequences of the T3SS pathogenicity island in 15 Acidovorax avenae strains. Consensus sequence and polymorphisms are indicated by green color and black vertical lines. Strains were color-coded by their hosts and phylogroups (green: maize, red: turfgrass group 1, blue: turfgrass group 2, black: Sa2). 
infect the same host. We'd like to address that the number of recombination events is estimated based on the phylogeny of a concatenated nucleotide sequence of the host-specific genes. It is possible that more recombination events occurred between closely related strains. However, due to the extremely low nucleotide diversity in the host-specific T3SS region, it is impossible for us to further quantify these events at the level of each individual gene.
Apart from the recombination event that allowed host specificity, we observe high recombination rates between A. avenae turfgrass strains but very limited recombination between turfgrass and maize strains. This suggests that most of the recombination events between the turfgrass-infecting strains occurred after the host shift of one of the A. avenae turfgrassinfecting clades, emphasizing the importance of frequent physical contact and sharing the same ecological niche for high

A

Whole genome

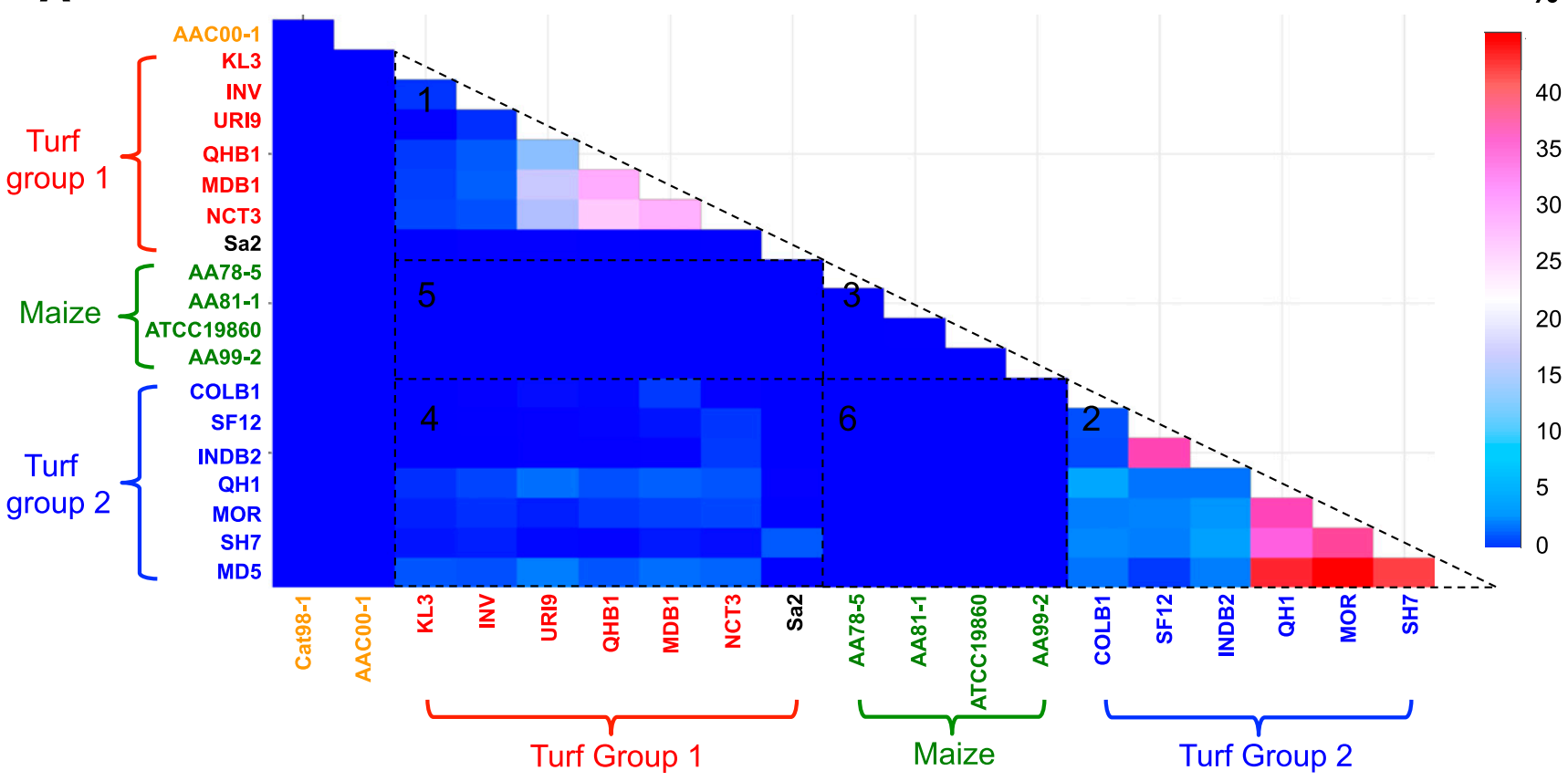

B

T3SS pathogenicity island

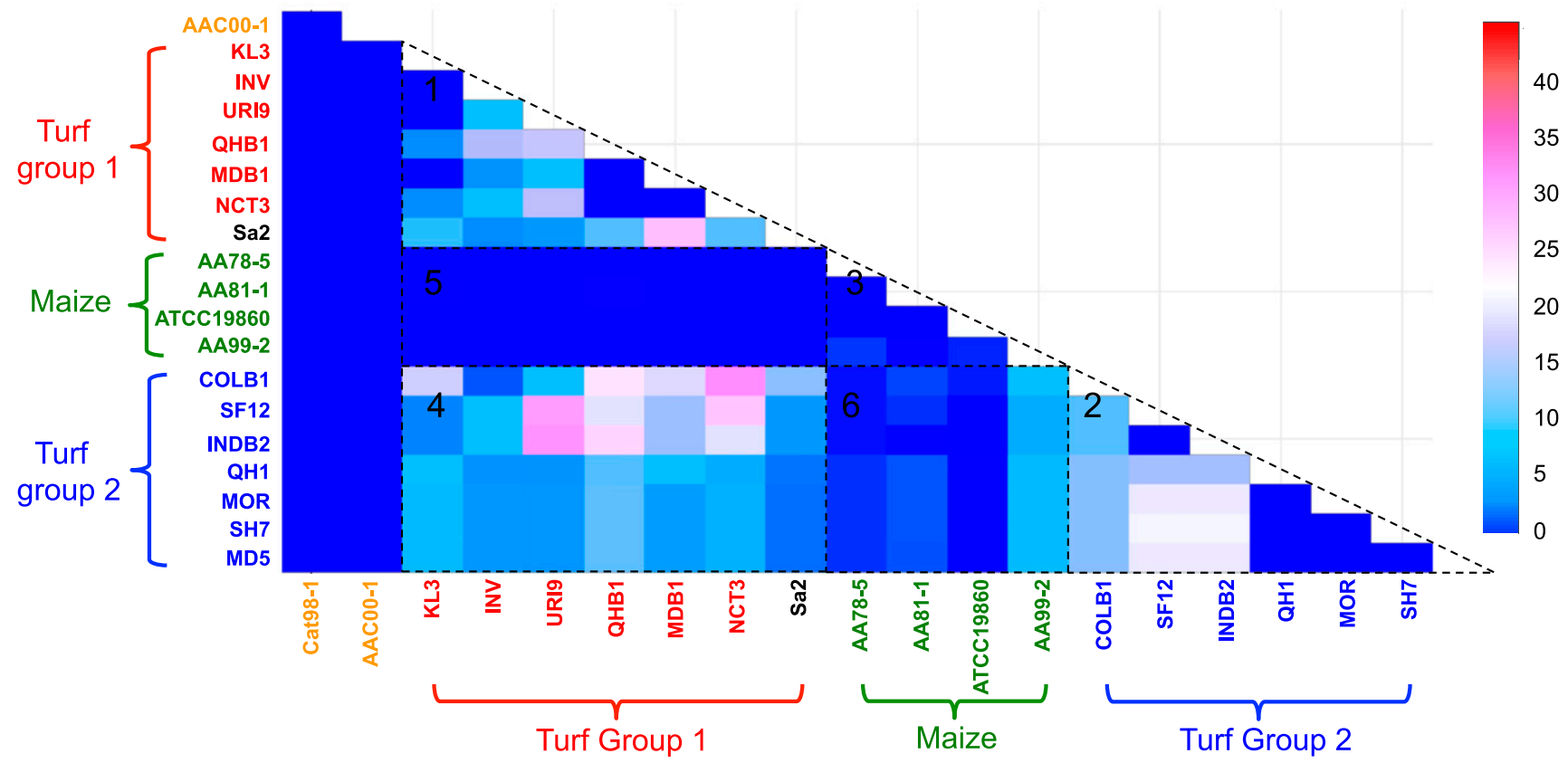

Fig. 7. Recombination occurred at the genome level and in the type III secretion system (T3SS) pathogenicity island. A, Percentage of the genome involved in gene conversions. B, Percentage of the T3SS pathogenicity island involved in gene conversions. The gene conversion fragments were identified by GENECONV, using the nucleotide alignment of the whole-genome sequences or the T3SS pathogenicity island sequences. Percentage was calculated by dividing the size of all gene conversion fragments with the size of the aligned sequences. Boxes numbered 1to 6 represent all possible combinations of different phylogroups. The simulated $P$ values of all gene conversion fragments are between 0 and 0.019 (for fragments detected in the genome, section A) and between 0 and 0.05 (for fragments detected in the T3SS pathogenicity island, section B). 
recombination rates. Hence, our data shows that host specificity can lead to differentiation (and eventually speciation) for bacterial strains that infect different hosts, but it can also lead to the opposite effect (convergent evolution) when two divergent clades infect a common host. We also show that purifying selection across the turfgrass-specific T3SS region is much stronger in turfgrass-infecting strains than in maize-infecting strains. The fact that the turfgrass-specific region is not conserved in maize supports suggestions that this region has not been affected by recombination with distantly related bacteria, because nucleotide diversity is identical to the mean diversity across the genome.

The sequence conservation we observed in the turfgrassspecific T3SS region is much higher than that of the rest of the genome. Our analyses show that this is likely due to strong purifying selection acting on this region of the genome. Previous studies have shown that purifying selection plays an important role in maintaining essential functions of the T3 secretion apparatus (Guttman et al. 2006; McCann and Guttman 2008). Results from this study provide evidence that purifying selection also helps in maintaining sequence conservation of host-specific alleles.

Here, we provide an example of two divergent pathogen lineages converging onto the same host by acquiring or maintaining, or both, a conserved set of virulence genes. However, this is not the only way that different lineages of pathogens adapt to the same host. The divergent pathogens may also be able to acquire different assemblages of virulence factors when adapting to the same host. For example, hazelnut decline in Greece and Italy was caused by two entirely distinct lineages of P. syringae pv. avellanae (Pav) (O'Brien et al. 2012). These two lineages of $P$. syringae pv. avellanae contain divergent T3 effector repertoires, which implies that the two lineages may have developed distinct mechanisms to infect hazelnut trees $\left(\mathrm{O}^{\prime} \mathrm{Brien}\right.$ et al. 2012). The reason for choosing different adaptive paths may be due to geography. The two pathogen lineages in Greece and Italy are geographically separated by the Ionian sea (allopatric speciation), whereas the two phylogroups of the turfgrass pathogens in this study are located in the same geographical region without any significant geographical barriers (sympatric speciation). It is conceivable that geographical barriers will play less of a role for pathogen evolution as globalization advances. Human activities and transportation of plant materials will provide ample opportunity for pathogens to share host-specific virulence factors on a global scale.

In conclusion, our study provides a comprehensive analysis of the bacterium $A$. avenae that has led to a recent outbreak of BED in turfgrass. We have shown that a diverse set of strains is responsible for causing the disease and have identified a set of genes that is likely to be responsible for conferring host specificity to turfgrass. Hence, here we provide the basis for developing tools to monitor and control the disease and, hopefully, prevent a more severe outbreak in the future.

Table 4. The ratios of nonsynonymous to synonymous substitutions (dN/dS) of genes located in the type III secretion system pathogenicity island in turfgrass Acidovorax avenae isolates

\begin{tabular}{|c|c|c|c|c|}
\hline GeneID $^{\mathbf{a}}$ & piDn & piDs & $d N / d S$ & $P$ value $^{b}$ \\
\hline Acav_0510 ${ }^{+}$ & 2.736 & 11.486 & 0.099 & 0.001 \\
\hline Acav_0511 ${ }^{+}$ & 2.431 & 7.778 & 0.114 & 0.001 \\
\hline Acav_0512 ${ }^{+}$ & 0 & 3.514 & 0 & 0.001 \\
\hline Acav_0513 ${ }^{+}$ & 4.375 & 14.806 & 0.095 & 0.001 \\
\hline Acav_0514 ${ }^{+}$ & 0 & 3.556 & 0 & 0.001 \\
\hline Acav_0515 ${ }^{+}$ & 0.972 & 6.75 & 0.047 & 0.001 \\
\hline Acav_0516 & 9.069 & 5.125 & 0.769 & 0.26 \\
\hline Acav_0517 ${ }^{+}$ & 4.792 & 5.167 & 0.334 & 0.005 \\
\hline Acav_0518 ${ }^{+}$ & 1.556 & 16.5 & 0.038 & 0.001 \\
\hline Acav_0519 ${ }^{+}$ & 1.708 & 14.056 & 0.058 & 0.001 \\
\hline Acav_0520 & 7.806 & 2.139 & 1.347 & 0.809 \\
\hline Acav_0521 ${ }^{+}$ & 3.417 & 10.972 & 0.113 & 0.001 \\
\hline Acav_0523 & 1.472 & 0.444 & 1.647 & 0.965 \\
\hline Acav_0524 & 9.34 & 7.91 & 0.439 & 0.827 \\
\hline Acav_0525 ${ }^{+}$ & 5.076 & 4.174 & 0.738 & 0.005 \\
\hline Acav_0526 & 0 & 1.181 & 0 & 0.237 \\
\hline Acav_0527 ${ }^{+}$ & 1.333 & 1.847 & 0.19 & 0.001 \\
\hline Acav_0528 & 1.361 & 1.528 & 0.521 & 0.016 \\
\hline Acav_0529 & 0.778 & 0.931 & 0.275 & 0.242 \\
\hline Acav_0530 & 0.528 & 8.139 & 0.031 & 0.15 \\
\hline Acav_0531 ${ }^{+}$ & 0.153 & 1.764 & 0.061 & 0.001 \\
\hline Acav_0532 ${ }^{+}$ & 0.611 & 1.903 & 0.331 & 0.002 \\
\hline Acav_0533 & 1.028 & 0.486 & 1.102 & 0.089 \\
\hline Acav_0534 & 0.5 & 0 & No_dS & 0.715 \\
\hline Acav_0535 & 1.097 & 0.431 & 0.489 & 1 \\
\hline Acav_0536 & 0 & 0.444 & 0 & 0.356 \\
\hline Acav_0537 & 0 & 0.306 & 0 & 0.278 \\
\hline Acav_0538 & 0 & 0.306 & 0 & 0.047 \\
\hline Acav_0539 & 1.111 & 1.861 & 0.163 & 0.047 \\
\hline Acav_0540 ${ }^{+}$ & 0.278 & 2.472 & 0.034 & 0.003 \\
\hline Acav_0541 ${ }^{+}$ & 0.278 & 0.556 & 0.148 & 0.001 \\
\hline Acav_0542 & 3.472 & 10.194 & 0.134 & 0.131 \\
\hline Acav_0543 ${ }^{+}$ & 2.5 & 16.306 & 0.05 & 0.001 \\
\hline
\end{tabular}

\section{B Whole genome}

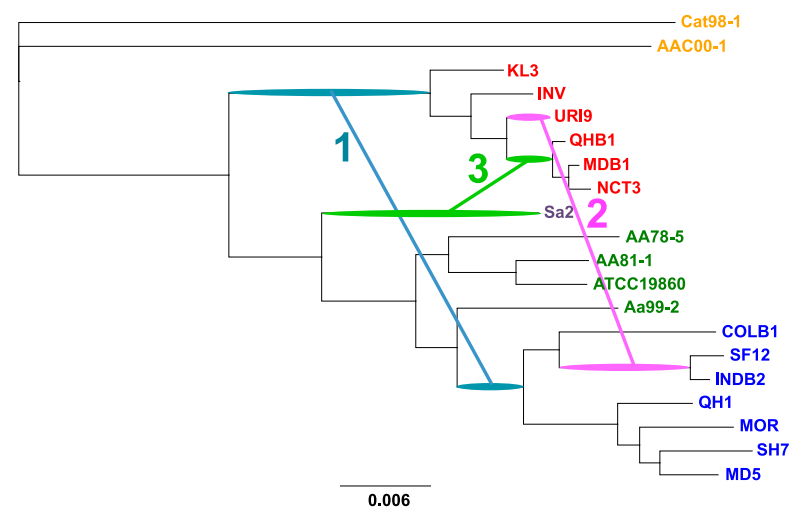

Fig. 8. Inference of the number of recombination events needed for the formation of the conserved type III secretion system (T3SS) gene cluster. A, Phylogeny of the concatenated nucleotide sequence alignment of Acav_0525 to Acav_0536. B, Whole-genome phylogeny indicating the only three recombination events necessary to explain difference between the host-specific T3SS tree and the whole-genome phylogeny. 


\section{MATERIALS AND METHODS}

\section{Bacterial strains.}

Acidovorax avenae isolates from creeping bentgrass were obtained from turfgrass samples with BED symptoms sent to the Michigan State University turfgrass diagnostic laboratory between 2009 and 2012. All other Acidovorax isolates were obtained from R. Walcott at the University of Georgia, except for isolates AA_30003 to AA30305 in Table 1, in which nucleotide sequences for individual genes were obtained from an Acidovorax multilocus sequence typing (MLST) database on the PAMDB website. Bacteria were cultured in lysogeny broth (LB) medium and stored at $-80^{\circ} \mathrm{C}$ in $15 \%$ of glycerol.

\section{DNA isolation.}

Bacterial strains were cultured in $5 \mathrm{ml}$ of $\mathrm{LB}$ broth at $28^{\circ} \mathrm{C}$. The bacterial cells were collected from a culture in exponential growth phase (optical density $=0.3$ ). Total DNA was isolated by using a Qiagen DNeasy kit (Qiagen, Valencia, CA, U.S.A.), following its protocol for bacterial DNA isolation. The quality and quantity of the purified DNA was checked by a Nanodrop 2000C (Nanodrop Products, Wilmington, DE, U.S.A.).

\section{MLSA.}

MLSA was performed as previously described by Feng et al. (2009). Briefly, a set of seven loci ( $g m c, u g p B$, pilT, lepA, trpB, $g l t A$, and $p h a C$ ) were polymerase chain reaction (PCR)-amplified from bacterial isolates originating in this study. The PCR products were purified using Exonuclease I (Fermentas Life Sciences, Vilnius, Lithuania) and FastAP Thermosensitive alkaline phosphatase (Fermentas Life Sciences), according to the manufacturer's protocol. DNA was sequenced at the Michigan State University Research Technology Support Facility, using an ABI 3730 automated sequencer. Sanger sequencing reads were assembled using the CodonCode Aligner (v. 2.0.6) (CodonCode Corporation, Centerville, MA, U.S.A.) to obtain $2 \times$ coverage sequences. All sequences were aligned using ClustalW in MEGA5 (Tamura et al. 2011). The sequences of seven genes are concatenated and are used in the ML analysis and Bayesian method of phylogenetic inference. The ML tree was generated using the general time reversible (GTR) model in Geneious 9.1.6 (Kearse et al. 2012).

Bayesian method of phylogenetic inference (Mau et al. 1999; Rannala and Yang 1996) was performed using MrBayes 3.3.2 (Ronquist and Huelsenbeck 2003). We assumed a GTR model with estimated parameter values for base frequencies, proportion of invariant sites, and for the shape of the gamma distribution with four categories. Ten million generations of two simultaneous Markov chain Monte Carlo chains were performed and trees were sampled every 500 generations. Four chains (three heated and one cold) were run, with heated chains at temperature of 0.2. Chain length, subsample frequency, and burn-in length are set at $1,100,000,200$, and 100,000, respectively. A. citrulli 00-1 was used as the outgroup.

\section{Genome sequencing and assembly.}

The quality and quantity of the DNA were measured using Agilent 2100 Bioanalyzer (Agilent Technologies, Sata Clara, CA, U.S.A.). The genomes of 15 Acidovorax strains (Cat98-1, KL3, INV, QHB1, MDB1, NCT3, Sa2, AA78-5, AA99-2, COLB1, SF12, INDB2, QH1, MOR, SH7) were sequenced using Illumina MiSeq technology at the Michigan State University Research Technology Support Facility. Genomic DNA was prepared using the Illumina TruSeq DNA library prep kit LT. Sequencing was performed on an Illumina MiSeq in a pair-end 250-bp read with a v2 reagent kit. The mean insert size of the 15 Acidovorax sequencing libraries ranged from 498 to $638 \mathrm{bp}$, with an average of $540 \mathrm{bp}$.

The Illumina sequencing files were first checked by FastQC to determine the sequencing quality. Trimmomatic v0.32 (Bolger et al. 2014) was used to trim off low-quality reads that do not meet the preset threshold. Reads that passed the filter were checked by FastQC again to confirm the improvement of quality from the original reads. The trimmed reads were then assembled by SPADEs de novo genome assembler v3.5.0 (Bankevich et al. 2012 ) into scaffolds with multiple K-mer lengths: $21,33,43,53$, 65 , and 77 . The de novo assembled genomes were analyzed by QUAST (Gurevich et al. 2013), using ATCC19860 as reference
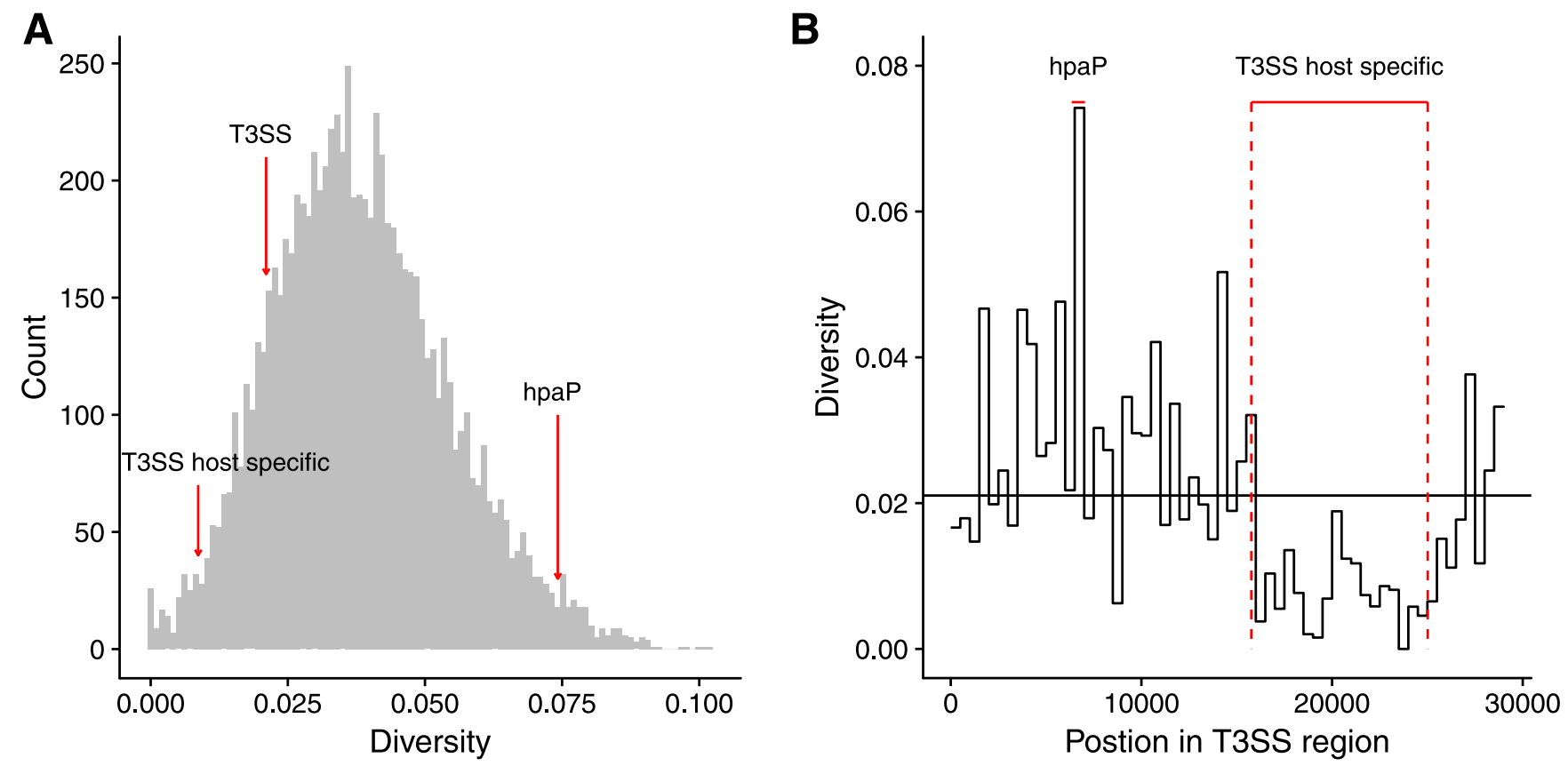

Fig. 9. Nucleotide diversity analysis across all 14 turfgrass-infecting Acidovorax avenae strains. A, Histogram of the mean per nucleotide diversity (Shannon entropy) calculated for nonoverlapping 500-bp long sequence windows across a REALPHY alignment for all 14 turfgrass-infecting A. avenae strains. Red arrows indicate the mean diversity for the type III secretion system (T3SS), the T3SS turfgrass-specific region, and for hpaP. B, The mean per nucleotide diversity across the T3SS region for nonoverlapping 500-bp sequence windows. 
genome. The assembled genomes (scaffolds) were ordered by MUMmer through the wrapper program ABACUS v 1.3.1 (Assefa et al. 2009). The pseudomolecules of all 15 genomes were generated and were used as input for gene annotation and prediction by Prokka v.1.11 (Seemann 2014).

Three A. avenae strains (MD5, URI9, and AA81-1) were sequenced using PacBio sequencing technology at the Yale Center for Genome Analysis. The library was prepared using the PacBio template preparation kit 1.0. Sequencing was performed on a PacBio RS II, using P6C4 reagent kit. One SMRT cell was used for each bacterial genome. The numbers of reads as well as the mean sequence lengths are 150,292 reads at 6,571 bp (MD5), 150,292 reads at $6210 \mathrm{bp}$ (URI9), and 150,292 reads at 8,253 bp (AA81-1). The genome coverage for the three strains are $86 \times, 84 \times$, and $111 \times$ (for MD5, URI9, and AA81-1, respectively). The genome sequences were assembled using the HGAP protocol of PacBio SMRT analysis software (Chin et al. 2013). The comparison of MD5, URI9, and AA81-1 was performed by MUMmer 3, using the default nucmer setting for fairly similar sequences (Kurtz et al. 2004).

Whole-genome alignment, SNP analyses, and phylogeny.

Fifteen assembled draft genomes (Cat98-1, KL3, INV, QHB1, MDB1, NCT3, Sa2, AA78-5, AA99-2, COLB1, SF12, INDB2, QH1, MOR, SH7) and five complete genomes (AA81-1, URI9, MD5, ATCC19860, AAC00-1) were used as input for a reference sequence alignment-based phylogeny (REALPHY) analysis (Bertels et al. 2014). REALPHY produced a merged alignment from five individual reference sequence alignments (Cat98-1, KL3, ATCC19860, QH1, SF12), using default parameters. From this alignment, a phylogeny was constructed with PhyML using a GTR substitution model as well as 100 bootstrap replicates (Guindon et al. 2005). The topology of the merged tree is the same as the consensus tree of the five individual reference trees (Felsenstein 1989). The merged tree was rooted using Cat98-1 and AAC00-1 as outgroups. The merged alignment of the 20 Acidovorax genomes generated from REALPHY was used as input file in Geneious 9.1.6 for determining the number of SNPs. Watterson's theta (Watterson 1975) was calculated using the Egglib package (De Mita and Siol 2012).

\section{Mapping turfgrass-pathogenic A. avenae by phylogroup and Mantel's test.}

The turfgrass-pathogenic A. avenae strains were mapped to the map of United States and color-coded by their phylogroups as determined by MLSA. Strains Sa2 and URI1 are separately listed because $\mathrm{Sa} 2$ was grouped as a separate clade in the genome-wide SNP alignment phylogeny. The pairwise genetic distance from the seven-gene MLST sequence alignment was calculated using the 'ape' package (Paradis et al. 2004) in R with the TN93 evolutionary model (Tamura and Nei 1993). The pairwise geographical distance was calculated based on the GPS coordinates of the isolation origin, using the 'geosphere' package in R. Mantel's test was performed using the 'ape' package in $\mathrm{R}$ with 10,000 permutations.

\section{Population test and virulence assay.}

The population test of $A$. avenae strains on maize was performed as follows. Two-week-old maize seedlings (Zea mays 'Peach Cream') grown from seed in Promix potting soil (Quakertown, PA, U.S.A.) were used in the inoculation assay. Acidovorax overnight cultures were adjusted to a cell concentration of $10^{8} \mathrm{CFU} \mathrm{ml} \mathrm{m}^{-1}$. Inoculation was performed by dipping sterile scissors into a bacterial suspension and cutting the tip of the second expanded leaf off, across the veins. The inoculated plants were kept in a temperature- and humidity-controlled growth chamber ( 26 and $22^{\circ} \mathrm{C}$ day and night temperatures, $80 \%$ humidity). The plants were surface-sterilized and pathogen population was sampled by plating at $72 \mathrm{~h}$ postinoculation. Statistical analysis was performed using the one-way analysis of variance (ANOVA) model in the 'stats' package in R. Letters above the bars denote the level of significance $(\alpha=0.05)$. For virulence phenotype observation, the inoculated maize leaves were collected 7 days after inoculation and virulence phenotype was documented.

The population test of $A$. avenae strains on turfgrass was performed as follows. Five-week-old creeping bentgrass (Agrostis stolonifera 'Penn A4') grown in horticultural grade perlite was used in the population assay. Prior to inoculation, whole plants were disinfested in 10\% sodium hypochlorite for $1 \mathrm{~min}$, followed immediately by a rinse in sterile distilled water for $1 \mathrm{~min}$. Top growth from individual plants was trimmed with a sterile razor blade so that each plant measured $20 \mathrm{~mm}$ from the crown. Lower roots were sliced with a sterile razor blade so that all roots measured $10 \mathrm{~mm}$ in length from the longest root tip to the crown. One milliliter of overnight culture of $A$. avenae strains $\left(10^{8} \mathrm{CFU}\right.$ $\mathrm{ml}^{-1}$ ) was added into each well of a 48-well flat-bottomed, polystyrene Costar cell culture plate (Corning Inc., Corning, NY, U.S.A.). Plates were covered with pierceable adhesive sealing foil and were punctured with a sterile pipette tip in the center of the well to accommodate plant insertion. The prepared creeping bentgrass was placed into each well of a 48-well plate and was incubated at $32^{\circ} \mathrm{C}$ with $80 \%$ humidity. Populations of $A$. avenae internally present in each plant were sampled at $72 \mathrm{~h}$ postinoculation, by plating. Statistical analysis was performed using the one-way ANOVA model in the 'stats' package in R. Plants for survival rate testing were kept at $32^{\circ} \mathrm{C}$ and survival rates were documented at $4,7,11,13,15$, and 17 days postinoculation. For virulence phenotype observation, six-week-old creeping bentgrass (Agrostis stolonifera 'Penn A4') grown in Promix potting soil in foam cups was first cut by sterile scissors and was then inversely dipped in bacterial suspension $(0.5 \times$ phosphate buffered saline containing bacteria at the concentration $\left.10^{8} \mathrm{CFU} / \mathrm{ml}\right)$. Inoculated plants were maintained at $32^{\circ} \mathrm{C}$ with $80 \%$ humidity. The virulence phenotype was documented at $72 \mathrm{~h}$ postinoculation.

\section{Genome-wide identification of host-specific genes in turfgrass $A$. avenae.}

The core genome (genes that are shared across all strains) was determined for six turfgrass group 1 (KL3, INV, QHB1, MDB1, NCT3, URI9), seven turfgrass group 2 (SH7, QH1, MOR, COLB1, INDB2, SF12, MD5), and four maize (AA78-5, AA99-2, AA81-1, ATCC19860) A. avenae strains. The protein sequences were used for core and pan genomes analyses, using Roary (Page et al. 2015) with a BLASTp identity cutoff of $80 \%$ for the comparison among Acidovorax strains. Homologs with at least $80 \%$ protein sequence identity that are present in at least 13 of the 20 Acidovorax strains were used to identify genes with sequence conservation in turfgrasspathogenic $A$. avenae strains (group 1 and group 2 strains and Sa2). Nucleotide sequences were aligned using MUSCLE v3.8.31 (Edgar 2004) and built gene trees using 'FastTree' (Price et al. 2009) with the neighbor joining method (Saitou and Nei 1987). Gene trees were analyzed in the 'ape' package to identify monophyletic groups that cluster strains adapted to the turf host. The monophyletic gene trees were further filtered by visualizing tree topologies in $\mathrm{R}$ using the 'ggtree' package (Yu et al. 2016), with tree tip labels colored according to their host range and phylogroups. Tree topologies that cluster turfgrass-pathogenic A. avenae strains (group 1 and group 2 strains and $\mathrm{Sa} 2$ ) apart from the maize-pathogenic strains were selected as gene candidates for $A$. avenae turfgrass host-specific genes. The procedure was implemented in $\mathrm{R}$ (3.1.3).

\section{Recombination test.}

The genome alignments of 20 Acidovorax strains generated by REALPHY was used to test for recombination in a Phi test as implemented in SplitsTree (Huson and Bryant 2006). After confirming the existence of recombination, the alignment 
file was used as input file in GENCONV, with default settings (Sawyer 1989), to predict the locations of gene conversion fragments. The multiple-comparison corrected $P$ values representing the possibility of gene conversion events were calculated with 10,000 random permutations. Regions with $P<0.05$ were identified as significant gene conversion fragments. The number of gene conversion fragments between two strains as well as the total size of these fragments were documented and displayed in heat maps generated by Plotly. Gene conversion fragments in the T3SS pathogenicity island were identified by the same method, using the DNA alignment of the T3SS pathogenicity island as input file. The visualization of DNA alignment of the T3SS pathogenicity island was performed in Geneious 9.1.6 (Kearse et al. 2012).

\section{Selection (dN/dS), Tajima's D, and nucleotide diversity analyses.}

The T3SS pathogenicity island sequences of 15 Acidovorax strains were extracted and aligned using MUSCLE (Edgar 2004). dN/dS ratios ( $\omega$ ) were calculated using EggLib (De Mita and Siol 2012) for each gene located within the T3SS pathogenicity island. Whether the deviation from a $\mathrm{dN} / \mathrm{dS}$ value of one was significant was determined for each gene's dN/dS value using Fisher's exact test.

To calculate the per nucleotide diversity, we generated a REALPHY alignment with URI9 as reference for all 13 turfgrassinfecting strains (without Sa2). For each nucleotide site, we calculated the Shannon entropy as follows.

$$
D_{j}=\sum_{i \text { inATGC }} p_{i j} \log _{2} p_{i j}
$$

where $D_{j}$ is nucleotide diversity for position $j$ in REALPHY alignment and $P_{i j}$ is the proportion of nucleotide $i$ in alignment at position $j$.

We calculated the mean nucleotide diversity over nonoverlapping 500-bp windows across the whole alignment.

\section{Presence and absence of putative virulence factors.}

The presence and absence of the genes with putative virulence functions in turfgrass-pathogenic A. avenae subsp. avenae were determined by applying BLAST (Altschul et al. 1997) to search for homologs of virulence-related genes in Acidovorax citruli AAC00-1 (NC_008752) and Acidovorax avenae ATCC19860 (NC_015138). Virulent related genes in AAC00-1 used to search with are T2SS genes gspl (Aave_4150-Aave_4160), gsp2 (Aave_0916-Aave_0926), endoglacanase gene (Aave_2102), and flagella genes (Aave_4383-Aave_4403). Virulent related genes in ATCC19860 used to search with are T4SS (Acav_0967-0971), T6SS (Acav_1504-1521), VgrG proteins (Acav_0298, Acav_0662, Acav_2399, Acav_3111, Acav_3369, Acav_3676, Acav_3724, Acav_1905), and T3SS (Acav_0510-0543). Putative T3 effectors in turfgrass-pathogenic $A$. avenae subsp. avenae were identified by performing BLAST of turfgrass-pathogenic A. avenae subsp. avenae using the amino acid sequences of effectors identified in Acidovorax citruli and closely related species (genera Xanthomonas, Pseudomonas, and Ralstonia). BLAST was performed using Geneious 9.1.6. The amino acid sequences of Acav_0510Acav_0543 of the turfgrass pathogen URI9 were searched in the EffectiveDB using default parameters for the T3 secretion prediction (Eichinger et al. 2016). Default prediction settings were used (Effective T3: minimal score $=0.9999,2.0 .1$ model; Effective ELD [based on eukaryotic-like domains] minimal score $=4$ ). Only predictions with high confidences were included in the results.

\section{ACKNOWLEDGMENTS}

We thank G. Wang and the Yale Center for Genome Analysis and K. Carr and the Michigan State University Research Technology Support Facility for performing genome sequencing for this work. We thank N. Dykema, R. Detweiler, C. Vossbrinck, M. Hoang and P. Sim for their technical support. We thank W. H. Elmer and the anonymous reviewers for their critical review of this paper. This research was supported by the United States Department of Agriculture-Hatch grant to Q. Zeng (CONH00650) and by the United States Golf Association Green Section Research to P.R. Giordano.

\section{LITERATURE CITED}

Ailloud, F., Lowe, T., Cellier, G., Roche, D., Allen, C., and Prior, P. 2015. Comparative genomic analysis of Ralstonia solanacearum reveals candidate genes for host specificity. BMC Genomics 16:270.

Altschul, S. F., Madden, T. L., Schäffer, A. A., Zhang, J., Zhang, Z., Miller, W., and Lipman, D. J. 1997. Gapped BLAST and PSI-BLAST: A new generation of protein database search programs. Nucleic Acids Res. 25:3389-3402.

Assefa, S., Keane, T. M., Otto, T. D., Newbold, C., and Berriman, M. 2009. ABACAS: Algorithm-based automatic contiguation of assembled sequences. Bioinformatics 25:1968-1969.

Awadalla, P. 2003. The evolutionary genomics of pathogen recombination. Nat. Rev. Genet. 4:50-60.

Balter, M. 2007. Plant science. Seeking agriculture's ancient roots. Science 316:1830-1835.

Baltrus, D. A., McCann, H. C., and Guttman, D. S. 2017. Evolution, genomics and epidemiology of Pseudomonas syringae: Challenges in bacterial molecular plant pathology. Mol. Plant Pathol. 18:152-168.

Baltrus, D. A., Nishimura, M. T., Dougherty, K. M., Biswas, S., Mukhtar, M. S., Vicente, J., Holub, E. B., and Dangl, J. L. 2012. The molecular basis of host specialization in bean pathovars of Pseudomonas syringae. Mol. Plant-Microbe Interact 25:877-888.

Bankevich, A., Nurk, S., Antipov, D., Gurevich, A. A., Dvorkin, M., Kulikov, A. S., Lesin, V. M., Nikolenko, S. I., Pham, S., Prjibelski, A. D. Pyshkin, A. V., Sirotkin, A. V., Vyahhi, N., Tesler, G., Alekseyev, M. A., and Pevzner, P. A. 2012. SPAdes: A new genome assembly algorithm and its applications to single-cell sequencing. J. Comput. Biol. 19:455-477.

Bertels, F., Silander, O. K., Pachkov, M., Rainey, P. B., and van Nimwegen, E. 2014. Automated reconstruction of whole-genome phylogenies from short-sequence reads. Mol. Biol. Evol. 31:1077-1088.

Bolger, A. M., Lohse, M., and Usadel, B. 2014. Trimmomatic: A flexible trimmer for Illumina sequence data. Bioinformatics 30:2114-2120.

Bonos, S.A., and Murphy, J.A. 2009. Bentgrass cultivars for golf course turf. Bulletin E324. New Jersey Agricultural Experiment Station, Rutgers, NJ, U.S.A.

Bruen, T. C., Philippe, H., and Bryant, D. 2006. A simple and robust statistical test for detecting the presence of recombination. Genetics 172:2665-2681.

Büttner, D., and He, S. Y. 2009. Type III protein secretion in plant pathogenic bacteria. Plant Physiol. 150:1656-1664.

Chin, C. S., Alexander, D. H., Marks, P., Klammer, A. A., Drake, J., Heiner, C., Clum, A., Copeland, A., Huddleston, J., Eichler, E. E., Turner, S. W., and Korlach, J. 2013. Nonhybrid, finished microbial genome assemblies from long-read SMRT sequencing data. Nat. Methods 10:563-569.

Claflin, L. E., Ramundo, B. A., Leach, J. E., and Erinle, I. D. 1989 Pseudomonas avenae, causal agent of bacterial leaf stripe of pearl millet. Plant Dis. 73:1010-1014.

De Mita, S., and Siol, M. 2012. EggLib: Processing, analysis and simulation tools for population genetics and genomics. BMC Genet. 13:27.

Doebley, J. F., Gaut, B. S., and Smith, B. D. 2006. The molecular genetics of crop domestication. Cell 127:1309-1321.

Edgar, R. C. 2004. MUSCLE: Multiple sequence alignment with high accuracy and high throughput. Nucleic Acids Res. 32:1792-1797.

Eichinger, V., Nussbaumer, T., Platzer, A., Jehl, M. A., Arnold, R., and Rattei, T. 2016. EffectiveDB-updates and novel features for a better annotation of bacterial secreted proteins and Type III, IV, VI secretion systems. Nucleic Acids Res. 44 (D1):D669-D674.

Elliott, C. A. 1923. Bacterial stripe disease of proso millet. J. Agric. Res. 26:151-160.

Felsenstein, J. 1989. PHYLIP_Phylogeny inference package (Version 3.2). Cladistics 5:164-166.

Feng, J., Schuenzel, E. L., Li, J., and Schaad, N. W. 2009. Multilocus sequence typing reveals two evolutionary lineages of Acidovorax avenae subsp. citrulli. Phytopathology 99:913-920.

Fuyuya, N., Ito, T., and Tsuchiya, K. 2009. Occurrence of bacterial brown stripe of creeping bentgrass on golf course green in Kyushu. J. Fac. Agr. Kyushu U. 54:13-17.

Giordano, P. R., Chaves, A. M., Mitkowski, N. A., and Vargas, J. M. 2012 Identification, characterization, and distribution of Acidovorax avenae subsp. avenae associated with creeping bentgrass etiolation and decline. Plant Dis. 96:1736-1742. 
Giordano, P. R., Vargas, J. M., Detweiler, A. R., Dykema, N. M., and Yan, L. 2010. First report of a bacterial disease on creeping bentgrass (Agrostis stolonifera) caused by Acidovorax spp. in the United States. Plant Dis. 94:922.

Gitaitis, R. D., Stall, R. E., and Strandberg, J. O. 1978. Dissemination and survival of Pseudomonas alboprecipitans ascertained by disease distribution. Phytopathology 68:227-231.

Guindon, S., Lethiec, F., Duroux, P., and Gascuel, O. 2005. PHYML Online-A web server for fast maximum likelihood-based phylogenetic inference. Nucleic Acids Res. 33:W557-W559.

Gurevich, A., Saveliev, V., Vyahhi, N., and Tesler, G. 2013. QUAST: Quality assessment tool for genome assemblies. Bioinformatics 29:1072-1075.

Guttman, D. S., Gropp, S. J., Morgan, R. L., and Wang, P. W. 2006 Diversifying selection drives the evolution of the type III secretion system pilus of Pseudomonas syringae. Mol. Biol. Evol. 23:2342-2354.

Huson, D. H., and Bryant, D. 2006. Application of phylogenetic networks in evolutionary studies. Mol. Biol. Evol. 23:254-267.

Ikki-Shuppan. 2008. The number of golf courses in the world. Mon. J. Golf Manage. 300:1-3

Kadota, I. 1996. Studies on the pathogen of bacterial brown stripe of rice and its ecology. Bull. Hokuriku Natl. Agric. Experiment Stn. 38:113-171.

Kearse, M., Moir, R., Wilson, A., Stones-Havas, S., Cheung, M., Sturrock, S., Buxton, S., Cooper, A., Markowitz, S., Duran, C., Thierer, T., Ashton, B., Meintjes, P., and Drummond, A. 2012. Geneious basic: An integrated and extendable desktop software platform for the organization and analysis of sequence data. Bioinformatics 28:1647-1649.

Kurtz, S., Phillippy, A., Delcher, A. L., Smoot, M., Shumway, M., Antonescu, C., and Salzberg, S. L. 2004. Versatile and open software for comparing large genomes. Genome Biol. 5:R12.

Lemaire, C., De Gracia, M., Leroy, T., Michalecka, M., Lindhard-Pedersen, H., Guerin, F., Gladieux, P., and Le Cam, B. 2016. Emergence of new virulent populations of apple scab from nonagricultural disease reservoirs. New Phytol. 209:1220-1229.

Manns, T. F. 1909. The blade blight of oats - a bacterial disease. Ohio Agric. Exp. Stn. Res. Bull. 10:91-167.

Marcelletti, S., and Scortichini, M. 2016. Xylella fastidiosa CoDiRO strain associated with the olive quick decline syndrome in southern Italy belongs to a clonal complex of the subspecies pauca that evolved in Central America. Microbiology 162:2087-2098.

Martin, J. P., and Wismer, C. A. 1989. Red stripe. Elsevier, Amsterdam.

Mau, B., Newton, M. A., and Larget, B. 1999. Bayesian phylogenetic inference via Markov chain Monte Carlo methods. Biometrics 55:1-12.

McCann, H. C., and Guttman, D. S. 2008. Evolution of the type III secretion system and its effectors in plant-microbe interactions. New Phytol. 177:33-47.

McCann, H. C., Rikkerink, E. H., Bertels, F., Fiers, M., Lu, A., ReesGeorge, J., Andersen, M. T., Gleave, A. P., Haubold, B., Wohlers, M. W., Guttman, D. S., Wang, P. W., Straub, C., Vanneste, J. L., Rainey, P. B., and Templeton, M. D. 2013. Genomic analysis of the kiwifruit pathogen Pseudomonas syringae pv. actinidiae provides insight into the origins of an emergent plant disease. PLoS Pathog. 9:e1003503.

Menardo, F., Praz, C. R., Wyder, S., Ben-David, R., Bourras, S., Matsumae H., McNally, K. E., Parlange, F., Riba, A., Roffler, S., Schaefer, L. K., Shimizu, K. K., Valenti, L., Zbinden, H., Wicker, T., and Keller, B. 2016. Hybridization of powdery mildew strains gives rise to pathogens on novel agricultural crop species. Nat. Genet. 48:201-205.

Mhedbi-Hajri, N., Hajri, A., Boureau, T., Darrasse, A., Durand, K., Brin, C., Fischer-Le Saux, M., Manceau, C., Poussier, S., Pruvost, O., Lemaire, C., and Jacques, M. A. 2013. Evolutionary history of the plant pathogenic bacterium Xanthomonas axonopodis. PLoS One 8:e58474.

Monteil, C. L., Cai, R., Liu, H., Llontop, M. E., Leman, S., Studholme, D. J., Morris, C. E., and Vinatzer, B. A. 2013. Nonagricultural reservoirs contribute to emergence and evolution of Pseudomonas syringae crop pathogens. New Phytol. 199:800-811.

O’Brien, H. E., Thakur, S., Gong, Y., Fung, P., Zhang, J., Yuan, L., Wang, P. W., Yong, C., Scortichini, M., and Guttman, D. S. 2012. Extensive remodeling of the Pseudomonas syringae pv. avellanae type III secretome associated with two independent host shifts onto hazelnut. BMC Microbiol. 12:141.

Page, A. J., Cummins, C. A., Hunt, M., Wong, V. K., Reuter, S., Holden, M. T., Fookes, M., Falush, D., Keane, J. A., and Parkhill, J. 2015. Roary: Rapid large-scale prokaryote pan genome analysis. Bioinformatics 31:3691-3693.

Paradis, E., Claude, J., and Strimmer, K. 2004. APE: Analyses of phylogenetics and evolution in R language. Bioinformatics 20:289-290.

Price, M. N., Dehal, P. S., and Arkin, A. P. 2009. FastTree: Computing large minimum evolution trees with profiles instead of a distance matrix. Mol. Biol. Evol. 26:1641-1650.

Rannala, B., and Yang, Z. 1996. Probability distribution of molecular evolutionary trees: A new method of phylogenetic inference. J. Mol. Evol. 43:304-311.

Remigi, P., Anisimova, M., Guidot, A., Genin, S., and Peeters, N. 2011. Functional diversification of the GALA type III effector family contributes to Ralstonia solanacearum adaptation on different plant hosts. New Phytol. 192:976-987.

Roberts, J. A., Kerns, J. P., and Ritchie, D. F. 2015. Bacterial etiolation of creeping bentgrass as influenced by biostimulants and trinexapac-ethyl. Crop Prot. 72:119-126.

Roberts, J. A., Ritchie, D. F., and Kerns, J. P. 2016. Plant growth regulator effects on bacterial etiolation of creeping bentgrass putting green turf caused by Acidovorax avenae. Plant Dis. 100:577-582.

Ronquist, F., and Huelsenbeck, J. P. 2003. MrBayes 3: Bayesian phylogenetic inference under mixed models. Bioinformatics 19:1572-1574.

Rosen, H. R. 1922. A bacterial disease of foxtail (Chaetochloa lutescens). Ann. Mo. Bot. Gard. 9:333-402.

Saitou, N., and Nei, M. 1987. The neighbor-joining method: A new method for reconstructing phylogenetic trees. Mol. Biol. Evol. 4:406-425.

Sawyer, S. 1989. Statistical tests for detecting gene conversion. Mol. Biol. Evol. 6:526-538.

Schaad, N. W., Postnikova, E., Sechler, A., Claflin, L. E., Vidaver, A. K., Jones, J. B., Agarkova, I., Ignatov, A., Dickstein, E., and Ramundo, B. A. 2008. Reclassification of subspecies of Acidovorax avenae as A. Avenae (Manns 1905) emend., A. cattleyae (Pavarino, 1911) comb. nov., A. citrulli Schaad et al., 1978) comb. nov., and proposal of A. oryzae sp. nov. Syst. Appl. Microbiol. 31:434-446.

Seemann, T. 2014. Prokka: Rapid prokaryotic genome annotation. Bioinformatics 30:2068-2069.

Shakya, D. D., Vinther, F., and Mathur, S. B. 1985. Worldwide distribution of bacterial stripe pathogen of rice identified as Pseudomonas avenae. J. Phytopathol. 114:256-259.

Stevens, C., Bennett, M. A., Athanassopoulos, E., Tsiamis, G., Taylor, J. D., and Mansfield, J. W. 1998. Sequence variations in alleles of the avirulence gene avrPphE.R2 from Pseudomonas syringae pv. phaseolicola lead to loss of recognition of the AvrPphE protein within bean cells and a gain in cultivar-specific virulence. Mol. Microbiol. 29:165-177.

Stukenbrock, E. H., and McDonald, B. A. 2008. The origins of plant pathogens in agro-ecosystems. Annu. Rev. Phytopathol. 46:75-100.

Sumner, D. R., and Schaad, N. W. 1977. Epidemiology and control of bacterial leaf blight of corn (Pseudomonas avenae). Phytopathology 67:1113-1118.

Tamura, K., and Nei, M. 1993. Estimation of the number of nucleotide substitutions in the control region of mitochondrial DNA in humans and chimpanzees. Mol. Biol. Evol. 10:512-526.

Tamura, K., Peterson, D., Peterson, N., Stecher, G., Nei, M., and Kumar, S. 2011. MEGA5: Molecular evolutionary genetics analysis using maximum likelihood, evolutionary distance, and maximum parsimony methods. Mol. Biol. Evol. 28:2731-2739.

Touchon, M., Hoede, C., Tenaillon, O., Barbe, V., Baeriswyl, S., Bidet, P., Bingen, E., Bonacorsi, S., Bouchier, C., Bouvet, O., Calteau, A., Chiapello, H., Clermont, O., Cruveiller, S., Danchin, A., Diard, M., Dossat, C., Karoui, M. E., Frapy, E., Garry, L., Ghigo, J. M., Gilles, A. M., Johnson, J., Le Bouguénec, C., Lescat, M., Mangenot, S., Martinez-Jéhanne, V., Matic, I., Nassif, X., Oztas, S., Petit, M. A., Pichon, C., Rouy, Z., Ruf, C. S., Schneider, D., Tourret, J., Vacherie, B., Vallenet, D., Médigue, C., Rocha, E. P., and Denamur, E. 2009. Organised genome dynamics in the Escherichia coli species results in highly diverse adaptive paths. PLoS Genet. 5:e1000344.

Watterson, G. A. 1975. On the number of segregating sites in genetical models without recombination. Theor. Popul. Biol. 7:256-276.

Yan, S., Liu, H., Mohr, T. J., Jenrette, J., Chiodini, R., Zaccardelli, M., Setubal, J. C., and Vinatzer, B. A. 2008. Role of recombination in the evolution of the model plant pathogen Pseudomonas syringae pv. tomato DC3000, a very atypical tomato strain. Appl. Environ. Microbiol. 74:3171-3181.

Yang, B., Sugio, A., and White, F. F. 2005. Avoidance of host recognition by alterations in the repetitive and C-terminal regions of AvrXa7, a type III effector of Xanthomonas oryzae pv. oryzae. Mol. Plant-Microbe Interact 18:142-149.

Yu, G., Smith, D., Zhu, H., Guan, Y., and Lam, T.T.Y. 2016. ggtree: An R package for visualization and annotation of phylogenetic tree with different types of meta-data. Method. Ecol. Evol. 8:28-36.

\section{AUTHOR-RECOMMENDED INTERNET RESOURCES}

FastQC: http://www.bioinformatics.babraham.ac.uk/projects/fastqc GENCONV program: http://www.math.wustl.edu/ sawyer/geneconv 'geosphere' package in R: https://cran.r-project.org/web/packages/geosphere/ geosphere.pdf

MUMmer 3: http://mummer.sourceforge.net

PAMDB Acidovorax MLST database at (http://genome.ppws.vt.edu/cgibin/MLST/search_alleles.pl

Plotly website: https://plot.ly

REALPHY online tool: http://realphy.unibas.ch 